\title{
Assessment of the sensitivity of core / shell parameters derived using the single-particle soot photometer to density and refractive index
}

\author{
J. W. Taylor ${ }^{1}$, J. D. Allan ${ }^{1,2}$, D. Liu ${ }^{1}$, M. Flynn ${ }^{1}$, R. Weber ${ }^{3}$, X. Zhang ${ }^{3, *}$, B. L. Lefer ${ }^{4}$, N. Grossberg ${ }^{4}$, J. Flynn ${ }^{4}$, and \\ H. Coe ${ }^{1}$ \\ ${ }^{1}$ Centre for Atmospheric Science, School of Earth, Atmospheric and Environmental Sciences, University of Manchester, \\ Manchester, UK \\ ${ }^{2}$ National Centre for Atmospheric Science, University of Manchester, Manchester, UK \\ ${ }^{3}$ Georgia Institute of Technology, Atlanta, GA, USA \\ ${ }^{4}$ Department of Earth and Atmospheric Sciences, University of Houston, Houston, TX, USA \\ *now at: Department of Civil and Environmental Engineering, University of California, Davis, CA, USA
}

Correspondence to: J. W. Taylor (jonathan.taylor@manchester.ac.uk)

Received: 21 March 2014 - Published in Atmos. Meas. Tech. Discuss.: 5 June 2014

Revised: 13 February 2015 - Accepted: 9 March 2015 - Published: 9 April 2015

\begin{abstract}
Black carbon (BC) is the dominant absorbing aerosol in the atmosphere, and plays an important role in climate and human health. The optical properties and cloud condensation nuclei $(\mathrm{CCN})$ activity of soot depend on the amounts (both relative and absolute) of $\mathrm{BC}$ and non-refractory material in the particles. Mixing between these two components is often represented in models by a core / shell coated sphere. The single-particle soot photometer (SP2) is one of, if not the only, instrument capable of reporting distributions of both core size and coating thickness. Most studies combine the SP2's incandescence and $1064 \mathrm{~nm}$ scattering data to report coating properties, but to date there is no consistency in the assumed values of density and refractive index of the core that are used in these calculations, which can greatly affect the reported parameters such as coating thickness. Given that such data are providing an important constraint for model comparisons and comparison between large data sets, it is important that this lack of consistency is addressed.

In this study we explore the sensitivity of the reported coatings to these parameters. An assessment of the coating properties of freshly emitted, thermodenuded ambient particles demonstrated that a core density of $1.8 \mathrm{~g} \mathrm{~cm}^{-3}$ and refractive index of (2.26-1.26i) were the most appropriate to use with ambient soot in the Los Angeles area. Using these parameters generated a distribution with median shell / core ratio of $1.02 \pm 0.11$, corresponding to a median absolute
\end{abstract}

coating thickness of $2 \pm 8 \mathrm{~nm}$. The main source of statistical error in the single-particle data was random variation in the incandescence signals. Other than the sensitivity to core refractive index, the incandescence calibration was the main source of uncertainty when optically determining the average coatings. The refractive index of coatings was found to have only a minor influence.

This work demonstrates that using this technique the SP2 can accurately determine the average mixing state (externally or internally mixed) of ambient soot within the precision of the instrument calibration. Ambient coatings were measured up to a median shell / core ratio of $1.50 \pm 0.11$, meaning that this technique is able to resolve absolute changes in mixing state.

However, when different core parameters were used, the core / shell ratio and the coating thickness were shown to be offset by amounts that could be larger than the atmospheric variability in these parameters, though the results have a similar precision. For comparison, using the core parameters that resulted in the thickest coatings, on the same thermodenuded fresh particles as before, generated a median shell / core ratio of $1.39 \pm 0.11$, corresponding to a median absolute coating thickness of $30 \pm 8 \mathrm{~nm}$. These results must be taken into account when comparing $\mathrm{BC}$ coatings measured using this technique, or if using these data for optical or CCN calculations. 
We have determined the most appropriate values of $\mathrm{BC}$ density and refractive index to use to measure mixing state at $1064 \mathrm{~nm}$ where particle morphology has only a minor effect, but appropriate values to use for optical calculations of nonspherical particles at visible wavelengths will also be subject to similar, significant uncertainties. Without similar constraints as those provided here, constraining the behaviour of $\mathrm{BC}$ particles in models using field data will be subject to large systematic measurement uncertainties.

\section{Introduction}

Black carbon (BC) is a combustion-generated aerosol ubiquitous throughout the lower levels of the atmosphere. It is damaging to human health (Janssen et al., 2012) and has a warming effect on climate (Bond et al., 2013). Due to its strong absorption of visible light, $\mathrm{BC}$ has important effects on regional climate and meteorology near where it is emitted (Ramanathan and Carmichael, 2008), and reducing BC emissions could help to mitigate climate change and improve public health (Jacobson, 2002, 2010; Bond and Sun, 2005).

$\mathrm{BC}$ is co-emitted with primary organic aerosol and secondary aerosol precursors such as organic gases and $\mathrm{NO}_{\mathrm{x}}$ which, through coagulation and condensation, form an internal mixture that increases BC's cloud condensation nuclei (CCN) activity (Khalizov et al., 2009) and can amplify light absorption (Schnaiter et al., 2005). The concentric core / shell Mie model (Bohren and Huffman, 1983) is often used to represent the mixing state of $\mathrm{BC}$ due to its computational simplicity, and the limited quantitative measurements of particle shape. Within this model, coatings can act as a lens, focusing light onto the BC core. This effect has been observed in numerous laboratory studies (Schnaiter et al., 2005; Zhang et al., 2008; Cross et al., 2010; Shiraiwa et al., 2010). However, ambient measurements have shown mixed results. Lack et al. (2012) observed a mean enhancement of $\sim 40 \%$ in biomass burning emissions, but Cappa et al. (2012) (and subsequently Cappa et al., 2013) observed much smaller enhancements off the California coast. Measurements like these rely on the use of thermodenuders to remove all non-BC material, however these instruments are unable to remove refractory coatings such as salts, metals and some organics (Cappa et al., 2013), and nonrefractory aerosol may recondense after the heated section (Fuentes and McFiggans, 2012).

Cappa et al. (2013) showed that even when taking into account the limitations of thermodenuders, the calculated absorption enhancements exceeded their measurements. Comparisons to detailed optical models, which use more complex soot morphologies, show that the concentric core / shell model overestimates the absorption enhancement due to coatings (Adachi et al., 2010). However, these models also often show that the absorption of the core is underestimated when assumed to be spherical, as the core's centre is shielded by its edge (Liu et al., 2008; Kahnert et al., 2012). Absorption of a spherical core is also strongly sensitive to the core size distribution, which varies significantly between different BC sources (Huang et al., 2011; Kondo et al., 2011a; Sahu et al., 2012). Finally, absorption of BC in any morphology also depends on the assumed refractive index (Bond and Bergstrom, 2006). When taking into account all these effects, some of which oppose each other, there is little experimental evidence that the concentric core / shell model systematically over- or under-estimates absorption compared to more complex models, as the comparison depends on the properties (either measured or assumed) of the particles in question.

State-of-the-art climate models (e.g. Matsui et al., 2013) use 2-D matrices of particle diameter and BC mass fraction to represent the wide variety of sizes and mixing states of ambient particles. Within the core / shell model, these are analogous to distributions of core size and coating thickness. The single-particle soot photometer (SP2, Droplet Measurement Technologies, Boulder, CO, USA) has emerged as a technique for measuring the distributions of both cores and coatings. The SP2 quantifies refractory black carbon (rBC) mass on a single-particle basis, irrespective of coatings (Moteki and Kondo, 2007; Slowik et al., 2007). These data can then be used to generate distributions of $\mathrm{rBC}$ core diameter $\left(D_{\mathrm{C}}\right)$. The SP2 is also capable of measuring the scattering cross-section of $\mathrm{BC}$-containing particles before they evaporate in the laser beam which, when combined with a Mie core / shell scattering model, can be used to calculate the spherical-equivalent diameter of the whole particle $\left(D_{\mathrm{P}}\right)$ (Gao et al., 2007; Moteki and Kondo, 2008). This diameter can then be used to calculate optical properties (Gao et al., 2008; Schwarz et al., 2008b; Shiraiwa et al., 2008). Moteki and Kondo (2008) (and subsequently Kondo et al., 2011b) described a technique where coating properties were determined by comparing light scattering of the coated particle to that of the core, though this technique is not used here. Here, we consider the more widely used technique where coating properties are calculated using the scattering of the coated particle and the incandescence of the core (Gao et al., 2007). In literature, a range of different assumed $\mathrm{rBC}$ densities $\left(\rho_{\mathrm{C}}\right)$ and refractive indices $\left(n_{C}\right)$ have been used with this technique.

In this paper, we quantitatively evaluate the capability of the SP2 to determine mixing state using the incandescence/scattering technique, providing a sensitivity analysis of the derived coatings to the assumed density and refractive index of the core, as well as other key variables involved in the calculation. We do not assess the ability of the core / shell model to accurately predict optical properties when using the derived core and coating distributions, as this topic will be discussed in a future paper (Taylor et al., 2015). 


\section{Experimental setup}

\subsection{The Pasadena supersite}

CalNex-LA, part of the wider CalNex project (Ryerson et al., 2013), took place from 15 May-15 June 2010. The Pasadena supersite has previously been described in detail (Washenfelder et al., 2011; Hayes et al., 2013). Briefly, a wide array of aerosol and gas-phase instrumentation was deployed on the Caltech campus in Pasadena, CA, USA. Atmospheric composition at the site showed a strong weekday diurnal cycle. During the afternoon, an advected plume from the sourcerich western LA basin reached the site after around $3 \mathrm{~h}$ photochemical processing (Washenfelder et al., 2011). At other times, composition at the site was generally representative of fresher, more local emissions, which are found throughout the basin (Metcalf et al., 2012). Non-refractory aerosol composition was typical of a polluted, oxidizing urban environment, with secondary organics dominating during daylight hours, and strong nocturnal ammonium nitrate formation (Hayes et al., 2013). The main source of BC in the region is thought to be diesel emissions. Biomass burning did not strongly influence the site during the measurement period (Bahreini et al., 2012; Hayes et al., 2013).

The site was periodically impacted by emissions from a nearby loading area, specifically those from a large, dieselpowered forklift truck. These emissions caused short, but strong spikes in the SP2 time series, which were removed from the data set as they were not deemed representative of the ambient aerosol.

\subsection{Overview of sampling system}

The University of Manchester instrumentation consisted of an SP2, three-wavelength photoacoustic soot spectrometer (PASS-3, Droplet Measurement Technologies), Aethalometer AE-31 (Magee Scientific, Berkeley, CA, USA) and a sootparticle aerosol mass spectrometer (SP-AMS, Aerodyne Research Inc., Billerica, MA, USA), though only the SP2 and SP-AMS data are considered here. Figure 1 shows the sampling system used by these instruments during CalNex. A shared $10.1 \mathrm{~cm}$ inner-diameter common inlet, of PVC and aluminium construction, was used to sample from $6.9 \mathrm{~m}$ above ground level. A model 8450 air velocity transducer (TSI Incorporated, Shoreview, MN, USA) in the main inlet ensured flow remained laminar.

Air from the stack was sub-sampled $5.6 \mathrm{~m}$ down, perpendicular to the main inlet flow, and dried to $35 \%$ relative humidity using a Nafion drier (Perma Pure, Toms River, New Jersey, USA). The counterflow was provided by a compressor connected to a Hankison membrane drier. Super-micron particles were removed using an inline $\mathrm{PM}_{1}$ cyclone (URG Corporation, Chapel Hill, North Carolina, USA), through a $3 \mathrm{~m}$ long copper tube. The SP2, PASS-3, SP-AMS and Aethalometer were connected to the cyclone output by ap-

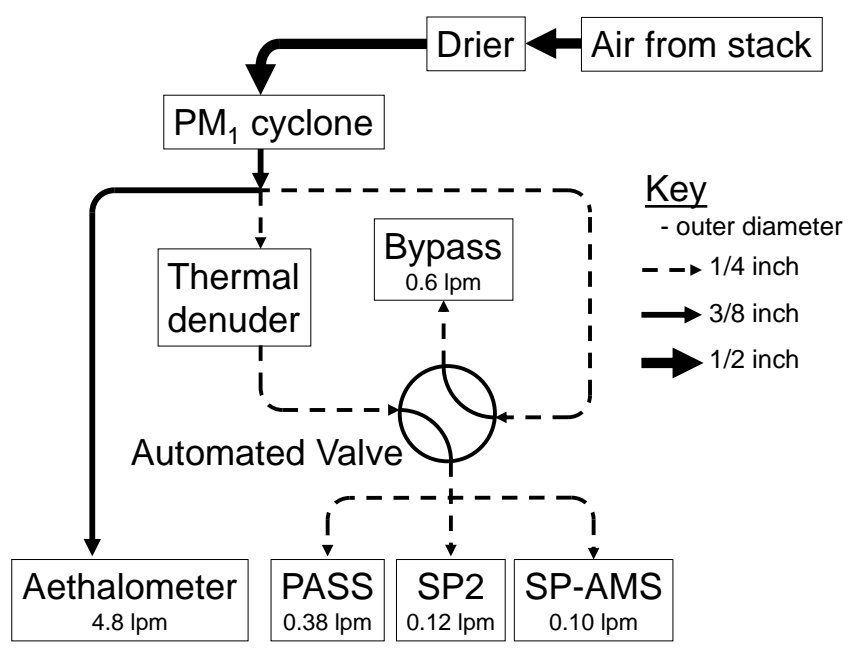

Figure 1. Schematic of the sampling system used for the University of Manchester instruments during CalNex, showing the instruments' sample flows. Stainless steel Y-pieces were used when splitting flows. Before the thermodenuder and bypass flow were set up, the Aethalometer flow rate was $5.4 \mathrm{~L} \mathrm{~min}^{-1}$ to ensure sufficient flow through the cyclone.

proximately $5 \mathrm{~m}$ of copper tube, as shown in Fig. 1. From 18 May 2010, the SP2, PASS-3 and SP-AMS sampled through a line, alternating every $10 \mathrm{~min}$ between an ambient inlet and a line drawn through a thermodenuder (Huffman et al., 2008). Before this date, only the ambient inlet was used.

\subsection{The single-particle soot photometer}

The SP2 (Stephens et al., 2003; Schwarz et al., 2010) measures $\mathrm{rBC}$ using the principle of laser-induced incandescence. Particles are drawn through a high-intensity intracavity $1064 \mathrm{~nm} \mathrm{Nd}$ : YAG laser; rBC-containing particles absorb the infrared laser radiation and are heated to incandescence, emitting visible light. $\mathrm{rBC}$ here is defined as the fraction of a soot particle that is thermally stable enough to incandesce before vaporizing (Petzold et al., 2013). Though $\mathrm{sp}^{2}$ carbon bonds are linked with both thermal stability and light absorption, it is not clear whether any non-carbon fraction of $\mathrm{BC}$ (such as refractory oxygen species) is included in rBC.

The incandescence light is detected on a particle-byparticle basis by two photomultiplier tubes (PMTs) which are optimized to different wavelength ranges (broadband and narrowband) to give an indication of the incandescence temperature (Schwarz et al., 2010). The amount of light detected is linearly proportional to the mass of black carbon in a particle, regardless of particle coatings or morphology (Moteki and Kondo, 2007; Slowik et al., 2007). The incandescence channels of the SP2 were calibrated using glassy carbon spheres (Type II, Alfa Aesar, Ward Hill, MA, USA) in the manner described by Liu et al. (2010) 
and McMeeking et al. (2010). The accuracy of the incandescence calibration was estimated at $\pm 14 \%$, corresponding to accuracy in average $D_{\mathrm{C}}$ of ${ }_{-4.9 \%}^{+4.5 \%}$. The SP2 also has two avalanche photodiode (APD) scattering detectors which were calibrated with polystyrene latex spheres (PSLs; Duke Scientific, now Thermo Fisher Scientific, Waltham, MA, USA). The scattering/coating data presented here were taken after 26 May 2010, when the SP2's detectors were re-aligned. Further details of SP2 calibrations are provided Sect. S1, in the Supplement.

During CalNex, the high-gain broadband detector measured particles with $\mathrm{rBC}$ mass between $0.2-27 \mathrm{fg}$ (67$305 \mathrm{~nm}$ mass-equivalent diameter at core density $\rho_{\mathrm{C}}=$ $1.8 \mathrm{~g} \mathrm{~cm}^{-3}$ ) and the low-gain narrowband detector measured particles with $\mathrm{rBC}$ mass $0.6-130 \mathrm{fg}(84-520 \mathrm{~nm})$. The $\mathrm{rBC}$ mass concentration was corrected for particles outside the SP2's detection range. Further details are provided in Sect. S2, in the Supplement. A comparison to a co-located Sunset OC / EC instrument is also presented in Sect. S3, in the Supplement. The SP2 showed excellent correlation $\left(R^{2}=0.94\right)$ with the optical EC channel, and good correlation $\left(R^{2}=0.58\right)$ with the more common thermal EC channel.

\subsection{The soot particle aerosol mass spectrometer}

The SP-AMS is a modified version of the HR-ToF Aerosol Mass Spectrometer (AMS; Aerodyne Research Inc., Billerica, Massachusetts, USA). The standard AMS utilizes a tungsten vaporizer heated to $600^{\circ} \mathrm{C}$, and hence cannot measure refractory species which remain solid at this temperature. The SP-AMS uses the same kind of $1064 \mathrm{~nm}$ Nd: YAG laser as in the SP2 to selectively vaporize BC-containing particles and measure their average composition as an ensemble (Onasch et al., 2012). During CalNex, the tungsten vaporizer was removed and so only $\mathrm{rBC}$-containing particles were vaporized. Note here that we are using the convention of referring to the BC material detected by the SP-AMS as $\mathrm{rBC}$ as recommended by Petzold et al. (2013), though it is not possible to unambiguously determine whether the sum of the carbon clusters measured by the SP-AMS is equivalent to the material detected by the SP2.

Mass concentrations were calculated using the standard fragmentation table technique (Allan et al., 2004), modified to account for $\mathrm{rBC}$ peaks at the mass/charge $(\mathrm{m} / \mathrm{z})$ channels at multiples of 12 , using an $\mathrm{rBC}$ relative ionization efficiency of 0.2 (Onasch et al., 2012). Where there was a conflict with other anticipated fragments (e.g. $\mathrm{C}_{3}^{+}$and $\mathrm{HCl}^{+}$at $m / z=36$ and $\mathrm{C}_{4}^{+}$and $\mathrm{SO}^{+}$at $m / z=48$ ), high-resolution analysis (DeCarlo et al., 2006) was employed to determine the $\mathrm{rBC}$ fraction as a function of time. While there were theoretically many contributions possible, the high-resolution analysis showed that the overwhelming majority of ambient $\mathrm{rBC}$ mass was accounted for by the $\mathrm{C}_{1}-\mathrm{C}_{4}$ fragments.

When attempting to quantify overall mass loadings, poor correlations were found when comparing the SP-AMS with the SP2 and Sunset instrument, in contrast to the measurements of Cappa et al. (2012). Upon investigation, it was found that the quantitative sensitivity of the SP-AMS to $\mathrm{rBC}$ was not independent of the other aerosol components. A greater fraction of the $\mathrm{rBC}$ was detected during periods of high concentrations of inorganics, which is speculatively linked to an improvement of the focusing of the particle beam with larger particles. This comparison is presented in Sect. S3.3, in the Supplement.

Because of this issue, it is not possible to treat the mass concentrations generated by the SP-AMS as absolute, however the relative concentrations reported (i.e. the ratios of the different aerosol species) should be accurate for those particles detected. These ratios are not necessarily representative of the BC-containing particles overall; the smaller particles that escape detection are likely to have a higher $\mathrm{rBC}$ to coating mass ratio. The addition of non-BC material would make them grow and become more spherical, and therefore stand a higher chance of being detected. The concentrations of coating materials relative to each other are likely to be more accurate, but it is likely to be biased slightly towards secondary rather than primary coatings. Primary coatings, such as those co-emitted with the BC will be prevalent on the missed particles and be almost purely organic as opposed to secondary coatings (those formed after emission) which are more likely to be mixed organic and inorganic. For the purposes of estimating the shell refractive index $\left(n_{S}\right)$, the relative mass fractions of the non-rBC SP-AMS species were used. While it is recognized that these ratios are more likely to be representative of the accumulation mode particles, there is no way of resolving this bias with these data.

\subsection{Thermodenuder and data averaging}

Semi-volatile aerosol was removed from the sample using a thermodenuder (Aerodyne Research Inc.; Huffman et al., 2008). Particles were drawn through a heated tube, and vapours were adsorbed onto a charcoal trap. The temperature was cycled on a sawtooth profile, heating from 56$230^{\circ} \mathrm{C}$ over $2 \mathrm{~h}$, with a $35 \mathrm{~min}$ cool-down period. Temperature was measured using three temperature probes; data were excluded when the standard deviation of the three measurements was $>4^{\circ} \mathrm{C}$, to reduce ambiguity in the internal temperature.

The SP2, PASS-3 and SP-AMS were switched between the thermodenuder and ambient inlet every $10 \mathrm{~min}$, with a bypass flow running through the unused line in order to maintain the temperature profile in the denuder and remove the need to flush out stagnant air after changes. The SP2 data were averaged to a $5 \mathrm{~min}$ time basis. Using the $1 \mathrm{~s}$ data, a $20 \mathrm{~s}$ delay time was observed between the valves switching and the sample line flushing through. Hence, data from the first $20 \mathrm{~s}$ of each $5 \mathrm{~min}$ period were excluded.

Losses through the thermodenuder were characterized by comparing the ratio of SP2 rBC mass and number concentra- 
tions to the average of the adjacent undenuded data points. Transmission of particles through the denuder exhibited a linear relationship with the thermodenuder temperature, parameterized by

Transmission $=0.728-0.0006 \times T_{\mathrm{TD}}$,

where $T_{\mathrm{TD}}$ is the average of the thermodenuder's three temperature probes, measured in ${ }^{\circ} \mathrm{C}$.

Though the slope is similar to that found by Huffman et al. (2008), the intercept is much less than 1 , which may be due to the use of a longer charcoal trap after the denuder. Number and mass losses measured by the SP2 were identical within $2 \%$ across the whole temperature range, suggesting that any size-dependence was negligible.

$\mathrm{rBC}$ and coating composition through the thermodenuder is presented in Sect. S4 in the Supplement. Though there were still some residual coatings, and the variable collection efficiency of the SP-AMS influenced some of the measurements, the majority of coating mass was removed when the thermodenuder was at its highest temperatures. In Sect. S5, we show that in the freshest air masses, particles thermodenuded to $>220^{\circ} \mathrm{C}$ could reasonably be considered externally mixed.

\subsection{Co-located $\mathrm{NO}, \mathrm{NO}_{2}$ and $\mathrm{NO}_{\mathrm{y}}$}

$\mathrm{NO}, \mathrm{NO}_{2}$ and $\mathrm{NO}_{\mathrm{y}}$ were measured by chemiluminescence using model 42C-TL detectors (Thermo Fisher Scientific) for $\mathrm{NO}$ and $\mathrm{NO}_{\mathrm{y}}$, and model 42i-TL for $\mathrm{NO}_{2}$. The $\mathrm{NO}_{2}$ instrument was modified to use a blue LED instead of a molybdenum catalyst to convert $\mathrm{NO}_{2}$ to $\mathrm{NO}$, to exclude conversion of $\mathrm{HNO}_{3}$ and peroxyacetyl nitrate (PAN) (Lefer et al., 2010). The $\mathrm{NO}_{\mathrm{y}}$ instrument was used as described by Luke et al. (2010), except that the molybdenum catalyst was only heated to $320^{\circ} \mathrm{C}$ to reduce possible interference from $\mathrm{NH}_{3}$ conversion. Data were reported as 1 min averages, and $\mathrm{NO}_{2}$ data were only available after 17:15 UTC on 27 May. $\mathrm{NO}_{\mathrm{x}}$ is calculated as the sum of $\mathrm{NO}$ and $\mathrm{NO}_{2}$. We calculate $-\log \left(\mathrm{NO}_{\mathrm{x}} / \mathrm{NO}_{\mathrm{y}}\right)$ as a qualitative measure of photochemical age (Kleinman et al., 2007), the method also used by Cappa et al. (2012). Data are only considered for periods when all three measurements $\left(\mathrm{NO}, \mathrm{NO}_{2}\right.$ and $\mathrm{NO}_{\mathrm{y}}$ ) were available.

\section{Calculating rBC coating thickness}

In the following section, we describe the data analysis routines and techniques required to use raw SP2 data to calculate $\mathrm{BC}$ coating properties. While the basic technique has been used before (Gao et al., 2007), here we explore the sensitivities of the Mie model to assumptions of density and refractive index, and describe data quality assurance techniques that are necessary for any comparison with measured optical properties.

\subsection{The use of the core / shell model}

Fresh soot particles often assume the form of fractal aggregates of BC spherules. Over time, mixing with other material by condensation and coagulation causes voids within the aggregates to be filled and the fractal shape to collapse to form a quasi-spherical particle (Zhang et al., 2008; Ghazi and Olfert, 2013). Given the variations in soot morphology, there is a question as to the representativeness of the core / shell model, and to the use of scattering to derive coating properties.

Adachi and Buseck (2013) measured the shapes of soot particles in Pasadena during the same measurement period as this study. While they observed a variety of morphologies and with variable mixing of material, heavily compacted (but uncoated) $\mathrm{BC}$ was seen in periods of high $\mathrm{CO}_{2}$ concentrations, which corresponded with the processed Western-LA plume reaching the site (Hayes et al., 2013). The dominant aerosol in these plumes was semi-volatile secondary organic aerosol (SOA), which Adachi and Buseck (2013) note they would be unable to detect as it would evaporate before or during the measurement process. Surface tension forces during condensation of coating material is thought to be the process by which fractal soot is compacted, so it therefore seems likely that these particles were coated by SOA that Adachi and Buseck (2013) were unable to detect.

How appropriate the use of light scattering is to derive coating properties depends on the particles in question. Particles small compared to the wavelength of light lie in the Rayleigh-Debye-Gans regime, where light scattering is independent of particle morphology. For a wavelength of $1064 \mathrm{~nm}$ used in the SP2, this regime is appropriate for externally mixed $\mathrm{BC}<\sim 10^{-20} \mathrm{~m}^{3}$ in volume (equivalent to $267 \mathrm{~nm}$ diameter) (Moteki et al., 2010). Externally mixed $\mathrm{BC}$ here means particles containing only $\mathrm{BC}$ - the mixing of more than one compound within single particles requires a distribution of refractive index, which is not accounted for in the simple Rayleigh-Debye-Gans approximation.

For thickly coated particles, which are quasi-spherical in shape due to compaction of the primary $\mathrm{BC}$ and filling in voids between spherules, laboratory measurements have shown that this method may be used to accurately determine the size of the coated particle (Shiraiwa et al., 2010). Laborde et al. (2013) also verified accurate sizing using this method for ambient particles with $<35 \% \mathrm{rBC}$ volume fraction when compared to particle mobility diameter.

For intermediate coatings, which may not exhibit a core shell morphology, the derived coating thickness is a useful qualitative indicator of mixing state that is widely used. Consideration of the scattering enhancement (compared to an uncoated particle) in any way more complex than a simple coating thickness would require detailed knowledge of particle morphology, measurements of which are extremely limited in terms of time resolution and their ability to measure semi-volatile coatings. Where soot of variable morphology 
is present, as is almost always the case in ambient environments, particle morphology would also need to be known on a single-particle basis as the particles were measured in the SP2.

Coating thicknesses derived using the core/shell Mie technique are therefore considered semi-quantitative in ambient environments. However, in order to be able to interpret these measurements, one needs to be able to accurately predict the amount of light scattered by externally mixed $\mathrm{rBC}$. Any enhancement of this amount would then indicate particles are mixed with some amount of nonrefractory material. When using the SP2's incandescence measurement to calculate the core size, the amount of light scattered then depends on the assumed refractive index and density of the core, as well as the calibration of the incandescence detectors. One must also carefully consider the limited detection range of the instrument (both its scattering and incandescence measurements) to avoid bias.

\subsection{Overview of technique}

For each particle, the incandescence signals are used to calculate the $\mathrm{rBC}$ mass, and the scattering signals provide the scattering cross-section of the coated particle at $1064 \mathrm{~nm}$, using the signals collected during the period between the particle beginning to interact with the laser beam and the point at which the particle starts to evaporate in the laser.

In order to calculate core and shell diameters, a number of parameters are required. A schematic overview of the calculation is shown in Fig. 2. The refractive index of the coating was calculated using the time-dependent chemical composition of the coating material measured by the SP-AMS. A number of lookup tables were generated for a range of different core and coating refractive indices, and thermally denuded data were used to constrain the most appropriate core density and refractive index, such that the measured scattering matched the modelled scattering if the cores were assumed to be uncoated. Size-dependent factors, such as small signals below detection limit or large signals saturating the detectors, could cause some of the scattering data to be considered unreliable. By examining the size dependence of these factors, a range of core diameters was identified for which the scattering data were considered reliable (see Sect. 3.4). Particles from this range were then used to calculate coating thicknesses.

\subsection{Determination of optical particle size using the SP2}

The SP2 uses two light scattering channels for optical sizing. When the laser and detectors are properly aligned, each purely-scattering particle records a Gaussian profile as it crosses the laser, with magnitude proportional to the laser intensity and scattering cross-section of the particle. For BCcontaining particles, material evaporates as they pass through the laser, causing the scattering cross-section to decrease to

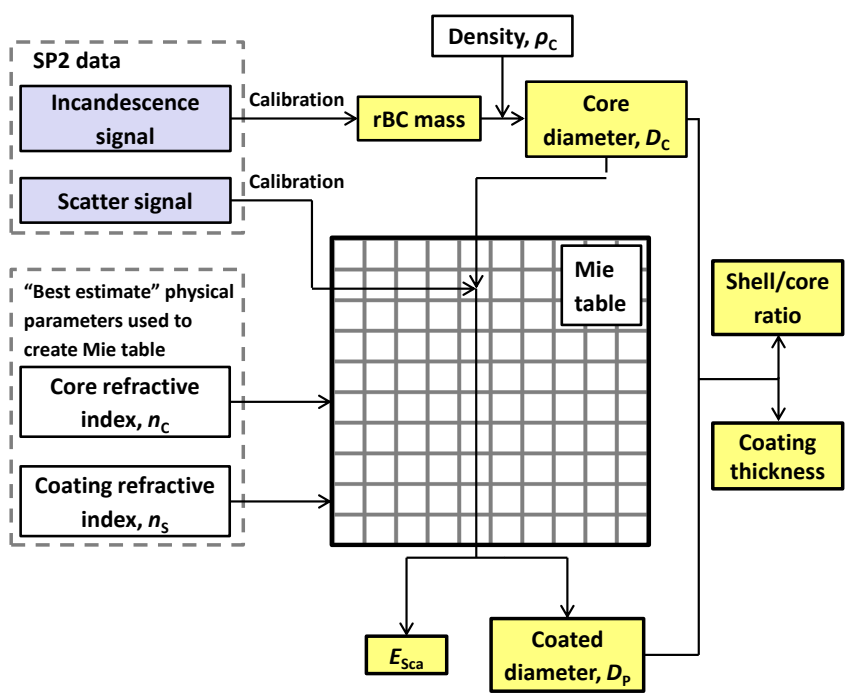

Figure 2. Overview of the input data/parameters and steps involved in calculating coating properties using SP2 data. Blue boxes represent the raw measured data, white boxes represent assumed parameters, and yellow boxes represent derived parameters.

zero. In order to properly size these particles, leading-edge only (LEO) fitting is used (Gao et al., 2007); the signal as the particles enter the edge of the laser, before material has evaporated, is used to reconstruct the Gaussian profile of the original particle, had it not evaporated. A two-element avalanche photodiode (TEAPD) was used to constrain the fits, such that the scattered light of the particle moves from one element of the detector to the other as it passes through the laser. The signal on one side is inverted, producing a clear notch as the particle passes the centre of the detector and the signal switches from negative to positive. The difference in position between the notch and the peak laser power is fixed during measurements, meaning that the position of a $\mathrm{BC}$ containing particle within the beam profile can be inferred to constrain the Gaussian fit as the Gaussian response of nonabsorbing particles is directly measured. For further explanation, the reader should refer to Laborde et al. (2012), where this scheme is presented graphically.

For each LEO fit, the baseline is calculated using the mean of the first six data points $(1.2 \mu \mathrm{s})$. The baseline is subtracted from the data, and a Gaussian function is then fit to the leading edge data. The modal notch position and width of the previous 200 unsaturated purely-scattering particles are used to constrain the fit, leaving the fit amplitude as the only free parameter. We define the leading edge as all data from the baseline-subtracted zero up to $5 \%$ of the maximum laser intensity, with the $x$ position calculated using the fit position and width assuming a Gaussian laser profile. The $5 \%$ threshold was determined by examining the time-dependent scattering cross section for incandescent particles (Moteki and Kondo, 2008; Laborde et al., 2012). 
A large fraction of particles evaporated before the notch position could be properly determined. Note that the incandescence signal is still reported for these particles, so this issue does not affect the $\mathrm{rBC}$ mass concentrations reported.

Gao et al. (2007) identified particles with scattering signals too small to reliably size, as they generate noisy fits, and those with large signals that saturated the scatter detector within the leading edge, as unreliable fits. Schwarz et al. (2008b) explored the effect of assuming the thinnest and thickest possible coatings for these particles, and reported coating properties as the average of these two extremes. In this analysis we avoid this issue by choosing the core diameter range in which particle coatings are considered such that these particles only make up a small fraction of particles, and do not affect derived coating properties. This range is discussed more fully in the next section. A series of filters was also used to identify and discard LEO fits that were poor due to electronic noise or coincident particles, though this issue affected $<0.01 \%$ of incandescence triggers.

\subsection{Determining a core size range for unbiased coating analysis}

In order to minimize bias in the results, it is necessary to examine the distribution of detectable notch position and good LEO fits vs. an independent variable, in this case the core diameter. The range of these parameters varies depending on the instrumental setup of the SP2.

Figure $3 \mathrm{a}$ shows the fraction of particles with detectable notch position $\left(F_{\text {Notch }}\right)$ as a function of $D_{\mathrm{C}}$. The smallest cores, $D_{\mathrm{C}}<100 \mathrm{~nm}$, show approximately $10 \%$ detectable notch position, as most particles in this size range do not scatter enough light to be detected by either scatter detector. The ambient particles show a higher $F_{\text {Notch }}$ than the denuded, as the ambient particles are, on average, more coated, and so a greater fraction of the smaller particles can be detected.

Figure $3 \mathrm{~b}-\mathrm{e}$ examine the probability distribution function of $E_{\mathrm{Sca}}$, the ratio of a particle's measured scattering crosssection divided by that of its uncoated core predicted by Mie theory, integrated over the detection angles of the SP2. Figure $3 \mathrm{~b}$ shows how $\mathrm{d} P / \mathrm{d} \log \left(E_{\text {Sca }}\right)$ varies with core diameter for the cases most influenced by fresh emissions. These are defined as particles which have passed through the thermodenuder set at a temperature greater than $220^{\circ} \mathrm{C}$, during periods when ambient $-\log \left(\mathrm{NO}_{\mathrm{x}} / \mathrm{NO}_{\mathrm{y}}\right)$ was lowest (defined as being less than 0.08 , the 10th percentile). These particles were the least chemically aged, and in Sect. S5 in the Supplement, we demonstrate that they had almost all of their coatings removed by the thermodenuder. Such particles with a $D_{\mathrm{C}}$ less than $100 \mathrm{~nm}$ show $E_{\text {Sca }}$ values greater than 1, as only the most coated particles are detected. Using data from this range of core diameter would result in a bias towards thickly coated particles.

At core diameters $100-135 \mathrm{~nm}, F_{\text {Notch }}$ increases and the distribution of $E_{\mathrm{Sca}}$ shifts closer to 1 as the bulk of BC-
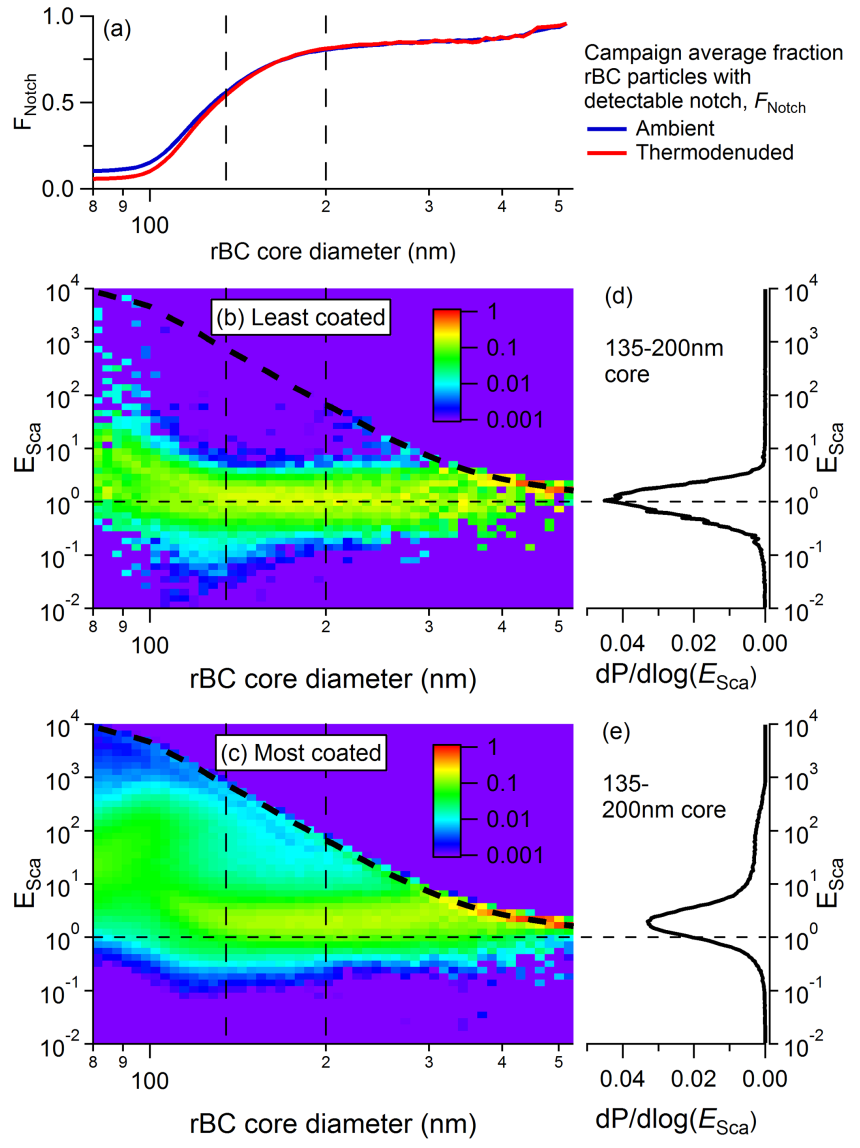

Figure 3. Diagnostics for determining the range of rBC core diameter used for Mie modelling. Panel (a) shows the fraction of rBCcontaining particles with detectable notch positions, averaged over the whole campaign, as a function of $D_{\mathrm{C}}$. Panels (b) and (c) show probability density functions, $\mathrm{d} P / \mathrm{d} \log \left(E_{\mathrm{Sca}}\right)$ for each core diameter bin, under the least processed (particles drawn through the thermodenuder $>220^{\circ} \mathrm{C}$ and $-\log \left(\mathrm{NO}_{\mathrm{x}} / \mathrm{NO}_{\mathrm{y}}\right)<10$ th percentile $)$ and most processed (ambient inlet and $-\log \left(\mathrm{NO}_{\mathrm{x}} / \mathrm{NO}_{\mathrm{y}}\right)>90$ th percentile) conditions respectively. The thick dashed black lines represent the calculated saturation of the scattering detector at $5 \%$ of maximum laser intensity. Panels (d) and (e) are $\mathrm{d} P / \mathrm{d} \log \left(E_{\mathrm{Sca}}\right)$ distributions for particles in the range $0.135 \leq D_{\mathrm{C}}<0.2 \mu \mathrm{m}$, bordered by the vertical dashed lines. The horizontal dashed lines show a core scatter ratio of 1 . Panels (b) and (c) are scaled in arbitrary units, and are normalized such that each column sums to 1 . Panels (d) and (e) are also normalized to sum to 1, though they are distributions over the range $0.135 \leq D_{\mathrm{C}}<0.2 \mu \mathrm{m}$, rather than averages of (b) and (c), and are thus weighted more heavily towards the smaller particles within the range. Panels $(\mathbf{b}-\mathbf{e})$ were calculated assuming $\rho_{\mathrm{C}}=1.8 \mathrm{~g} \mathrm{~cm}^{-3}$ and $n_{\mathrm{C}}=(2.26-1.26 i)$.

containing particles become detectable in both scatter detectors. At $D_{\mathrm{C}}=135 \mathrm{~nm}$ the two traces on Fig. 3a converge, and therefore $F_{\text {Notch }}$ is independent of coatings. This $D_{\mathrm{C}}$ is also the point where $F_{\text {Notch }}$ reaches $50 \%$. We choose this diameter as the lower bound of the region in which to consider LEO fitting. 
Figure $3 \mathrm{c}$ shows $\mathrm{d} P / \mathrm{d} \log \left(E_{\mathrm{Sca}}\right)$ vs. core diameter of particles sampled under the most processed conditions. Such conditions are defined as being when particles are sampled through the ambient inlet and the ambient $-\log \left(\mathrm{NO}_{\mathrm{x}} / \mathrm{NO}_{\mathrm{y}}\right)$ was greater than 0.34 (the 90th percentile). The upper edge of the $E_{\text {Sca }}$ distribution is limited by saturation of the lowgain scatter detector. It is clear that for large core sizes, a significant fraction of the most coated particles are limited by saturation. We choose $D_{\mathrm{C}}=200 \mathrm{~nm}$ as the upper bound of the region in which coatings are considered, in order to limit this bias affecting the data.

Although there is some user input in determining the $D_{\mathrm{C}}$ limits, we have detailed a logical method to determine reasonable values. For comparison, shifting the limits by $5 \mathrm{~nm}$ either way (i.e. $130 \leq D_{\mathrm{C}} \leq 195$ and $140 \leq D_{\mathrm{C}} \leq 205$ ) affected campaign-average coatings by $<1 \%$.

Figure $3 \mathrm{~d}$ and e show $\mathrm{d} P / \mathrm{d} \log \left(E_{\text {Sca }}\right)$ for $135 \leq$ $D_{\mathrm{C}} \leq 200 \mathrm{~nm}$ for the least coated and most coated particles respectively. While this range does not cover the entire $\mathrm{rBC}$ mass distribution, Fig. $3 \mathrm{~b}$ and $\mathrm{c}$ show minimal size dependence, other than the measurement limitations discussed previously, meaning that this range is likely representative of the majority of ambient absorbing aerosol. For our choice of density and refractive index, which are discussed in Sect. 3.6, the least coated particles show $E_{\text {Sca }}$ has a modal value close to 1 , signifying minimally coated particles, and for the most coated particles there is a clear shift towards larger $E_{\text {Sca }}$.

To summarize, scattering measurements on particles with the smallest core size detected by the SP2 are biased towards the most coated particles, whilst particles with the largest cores are biased towards the least coated. These are due to scattering signals being below the detection limit, or above the saturation level, of the scattering detectors. This section has outlined a method to choose a range of core diameters that are least affected by these problems, to gain the most representative results possible.

\subsection{The Mie model}

A scattering model is used to relate the measured scattering signal to particle diameter. For BC-containing particles, we assume a concentric sphere core-shell configuration, and use Mie theory to calculate the scattering cross-sections. We used Scattnlay Mie code (Pena and Pal, 2009), which uses the same equations developed by Yang (2003) but runs in C. For ease of use and computational efficiency, these algorithms were compiled as an external operation (XOP) for Igor Pro (Wavemetrics, Portland, OR, USA).

A series of 2-D lookup tables were produced containing scattering cross-sections for $\lambda=1064 \mathrm{~nm}$, integrated over the angles of the SP2's APDs (Moteki and Kondo, 2007), for core diameter $80 \leq D_{\mathrm{C}} \leq 600 \mathrm{~nm}$ and coated diameter $100 \leq D_{\mathrm{P}} \leq 600 \mathrm{~nm}$, with $1 \mathrm{~nm}$ resolution to reduce any truncation error. We were unable to reliably sample calibration particles larger than $600 \mathrm{~nm}$, so this size is considered the upper limit. The $80 \mathrm{~nm}$ lower limit was chosen as it is close to the lower cutoff diameter of the incandescence measurement. Different tables must be used for different core and shell refractive indices. For each particle, $D_{\mathrm{C}}$ is calculated using the incandescence data as described in Sect. 2.3 and $D_{\mathrm{P}}$ is then interpolated using the selected look-up table, normalized to the measured scattering signal of a $200 \mathrm{~nm}$ PSL. The most basic product of Mie theory in the context of the SP2 is $E_{\text {Sca }}$, the enhancement in a particle's scattering crosssection (integrated over the angles of the SP2's scatter detectors) compared to that of its uncoated core. To calculate $E_{\text {Sca }}$, only the $\mathrm{rBC}$ core density and refractive index are necessary, whereas calculating a coating thickness also requires the refractive index of the coating. Some particles recorded $E_{\text {Sca }}<1$, such that the LEO scattering signal is smaller than Mie theory predicts for an uncoated core. This value is equivalent to a negative coating thickness, which is nonphysical. These measurements are partly a consequence of random errors associated with the LEO fitting, but their likelihood is also strongly affected by the core density and refractive index used. This issue is discussed in the next section. In order to include these particles in coating calculations, they are assigned a coating thickness of zero. This approach does not affect the median shell / core ratio, though it may slightly bias any calculated bulk optical properties towards more coated particles. Discarding these particles would bias the data even further, as only the thickest coatings would be counted.

\subsection{Sensitivity to density and refractive index}

As noted in the previous section, calculation of $E_{\text {Sca }}$ requires prior knowledge of the density and complex refractive index of the $\mathrm{rBC}$ core. Using a higher refractive (real and imaginary) index increases the scattering efficiency of the $\mathrm{rBC}$ core, and consequently reduces the calculated $E_{\mathrm{Sca}}$. Conversely, the scattering cross-section of a particle of given mass scales approximately with $\rho_{\mathrm{C}}^{2 / 3}$, so increasing density increases $E_{\mathrm{Sca}}$. These two parameters have been the subject of a large body of previous research, extensively reviewed by Bond and Bergstrom (2006). They recommended densities between $1.7 \leq \rho_{\mathrm{C}} \leq 1.9 \mathrm{~g} \mathrm{~cm}^{-3}$ and refractive indices in the range $(1.75-0.63 i) \leq n_{\mathrm{C}} \leq(1.95-0.79 i)$ noting the higher refractive (real and imaginary) indices looked the most promising. More recently, Moteki et al. (2010) used SP2 LEO measurements to infer $n_{\mathrm{C}}=(2.26-1.26 i)$ for denuded ambient soot in Tokyo, assuming a density $\rho_{\mathrm{C}}=1.8 \mathrm{~g} \mathrm{~cm}^{-3}$. These parameters were used by Laborde et al. (2013) to explore the properties of rBC in Paris, and Taylor et al. (2014) in boreal biomass burning plumes. A variety of other parameters have been used in previous publications. These are discussed in Sect. S6, in the Supplement, and summarized in Table 1.

Figure 4 demonstrates the sensitivity of calculated scattering cross section of uncoated $\mathrm{rBC}$ cores to density and refractive index, using the parameters in Table 1. While there 
Table 1. Summary of core densities and refractive indices used in previous SP2 core / shell calculations.

\begin{tabular}{|c|c|c|c|c|}
\hline $\begin{array}{l}\text { Core density } \\
\left(\rho_{\mathrm{C}}, \mathrm{g} \mathrm{cm}^{-3}\right)\end{array}$ & Reference & $\begin{array}{l}\text { Core refractive } \\
\text { index } n_{\mathrm{C}}\end{array}$ & Reference & Studies used \\
\hline 1.8 & Bond and Bergstrom (2006) & $(2.26-1.26 i)$ & Moteki et al. (2010) & $\begin{array}{l}\text { This study } \\
\text { Laborde et al. (2013) } \\
\text { Taylor et al. (2014) }\end{array}$ \\
\hline 1.8 & Bond and Bergstrom (2006) & $(1.95-0.79 i)$ & Bond and Bergstrom (2006) & $\begin{array}{l}\text { Langridge et al. (2012) } \\
\text { Metcalf et al. (2012) }\end{array}$ \\
\hline 1.9 & Bond and Bergstrom (2006) & $(1.95-0.79 i)$ & Bond and Bergstrom (2006) & Subramanian et al. (2010) \\
\hline 1.77 & Park et al. (2004) & $(1.87-0.56 i)$ & Marley et al. (2001) & Shiraiwa et al. (2008) \\
\hline 2 & & $(2-1 i)$ & Schnaiter et al. (2005) & $\begin{array}{l}\text { Schwarz et al. (2008a) } \\
\text { Schwarz et al. (2008b) } \\
\text { Schwarz et al. (2009) }\end{array}$ \\
\hline 2 & Hess et al. (1998) & $(1.76-0.44 i)$ & Hess et al. (1998) & $\begin{array}{l}\text { Kondo et al. (2011a)* } \\
\text { Moteki et al. }(2012)^{*} \\
\text { Sahu et al. }(2012)^{*}\end{array}$ \\
\hline
\end{tabular}

* These studies used the scattering-only technique to derive coating thickness, but the values are included here for comparison.

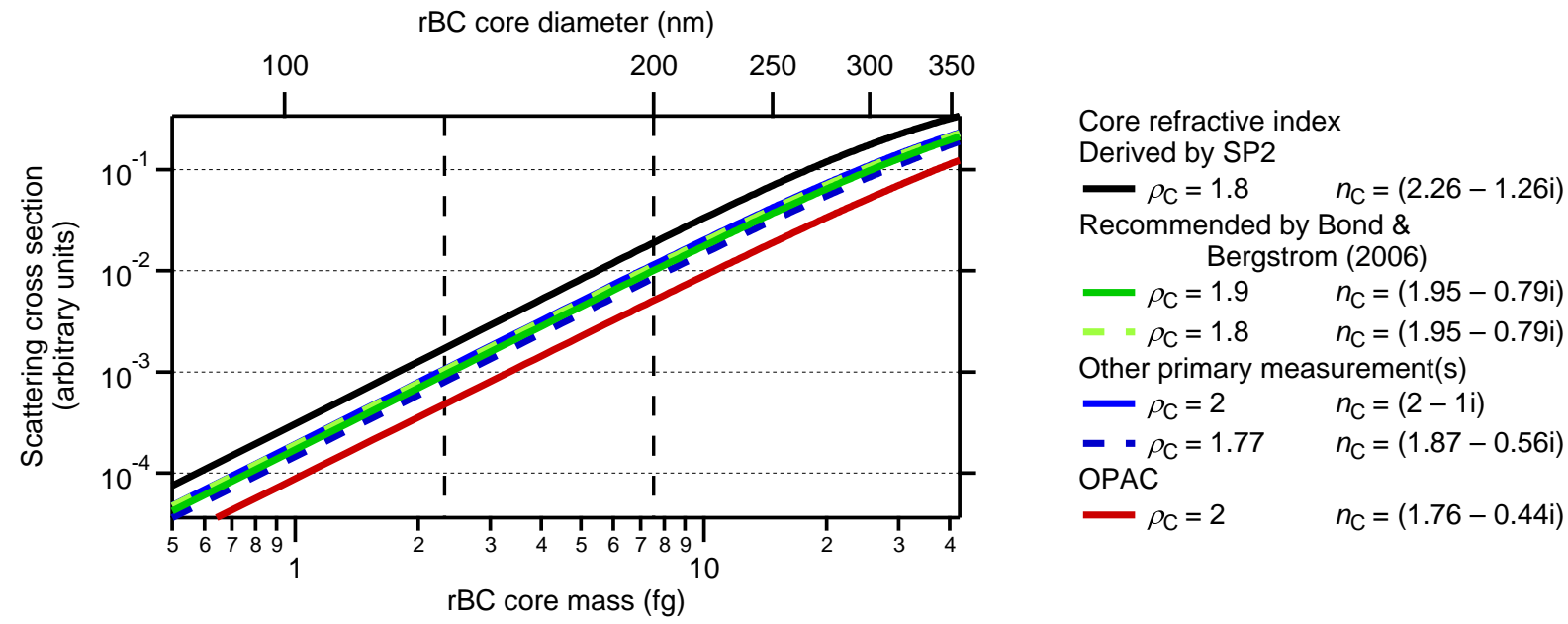

Figure 4. Calculated scattering cross-section, integrated over the angles of the SP2's scatter detectors, for the different combinations of density and refractive index used in previous SP2 ambient core / shell modelling. Densities are in units of $\mathrm{g} \mathrm{cm}^{-3}$. The vertical dashed lines bound the range of core diameter used for coating calculations in this study. The solid blue and dashed green lines partially overlap.

appears to be a central group of similar cross sections, the difference between the highest and the lowest is a factor of 3 . This equates to a difference in a factor of 3 when calculating $E_{\text {Sca }}$, and hence a significant change in calculated coating thickness (see Sect. 4). The effect this difference has on the measured distribution of $E_{\text {Sca }}$ is shown in Fig. 5a for particles measured during the same least-processed conditions as presented in Fig. 3.

The fact that the spread in $E_{\mathrm{Sca}}$ is similar regardless of the core parameters used means that the main source of perparticle noise is in the raw data and/or LEO fitting. The spread in the data is due to a combination of random error in the LEO fits, particles passing through different parts of the laser, and uncertainty in $D_{\mathrm{C}}$. The per-particle statistical uncertainty in rBC mass is $\pm 30 \%$ (equivalent to ${ }_{-11 \%}^{+9 \%}$ in $D_{\mathrm{C}}$ ).
As scattering scales roughly with diameter to the sixth power, this uncertainty suggests a per-particle uncertainty in $E_{\text {Sca }}$ of ${ }_{-50 \%}+70 \%$ from incandescence noise. The per-particle noise in the LEO fits during PSL calibrations was $\pm 40 \%$, meaning that the main source of per-particle noise in $E_{\text {Sca }}$ and any derived coatings is the incandescence channel.

Ideally, the $E_{\text {Sca }}$ distribution should be centred around 1 for uncoated particles. The fraction of particles with $E_{\text {Sca }}<1$ is strongly dependent on the core refractive index, as would be the bias associated with discarding these particles for coating calculations.

Using the density and refractive index recommended by Moteki et al. (2010), measured by a similar technique using the SP2's scattering measurement, results in a distribution centred close to 1 . Moteki et al. (2010) conducted their 

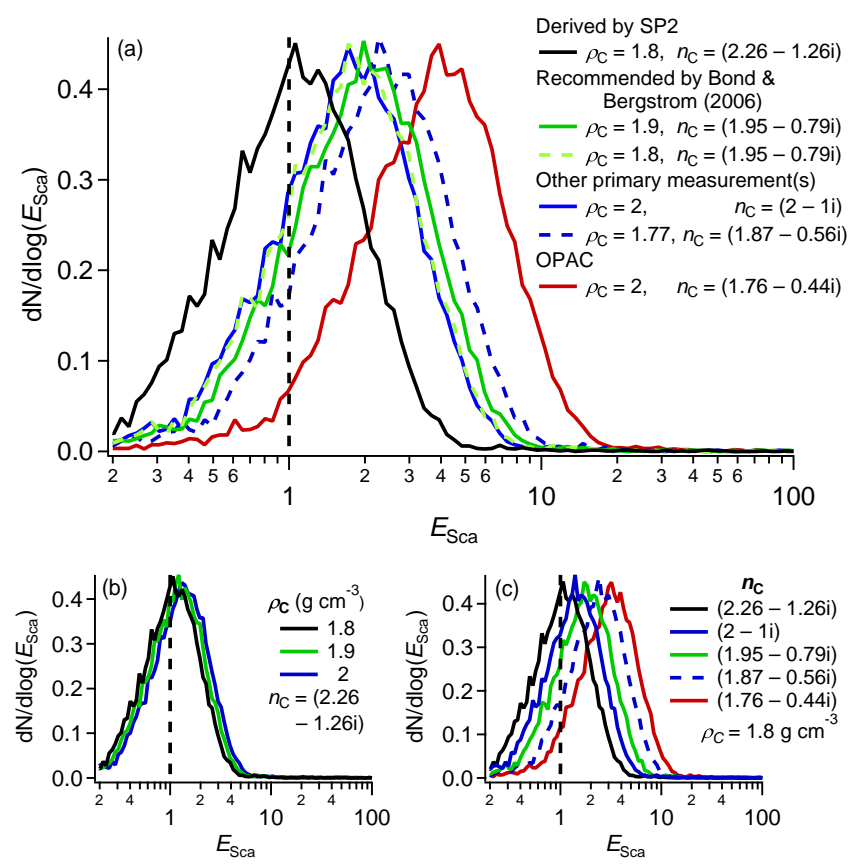

Figure 5. Normalized $E_{\text {Sca }}$ distribution, in arbitrary units, for the least coated particles (thermodenuder $>220^{\circ} \mathrm{C}$ and $-\log \left(\mathrm{NO}_{\mathrm{x}} / \mathrm{NO}_{\mathrm{y}}\right)<10$ th percentile) for different $\mathrm{rBC}$ core densities and refractive indices. Panel (a) shows data for density (in units of $\mathrm{g} \mathrm{cm}^{-3}$ ) and refractive index combinations used in previous SP2 core / shell modelling, whilst panels (b) and (c) illustrate the sensitivity to core density and refractive index respectively.

measurements at $1064 \mathrm{~nm}$, whereas the others were either for visible wavelengths or broadband spectra. We therefore consider the parameters derived by Moteki et al. (2010) the most appropriate to use for this data set and other SP2 measurements where diesel engines are the dominant source of $\mathrm{BC}$. Under the assumption that they represent the closest estimate to the physical properties of the measured $\mathrm{rBC}$, all other parameters tested in Fig. 5a led to an overestimation of $E_{\mathrm{Sca}}$, and further analysis would therefore overestimate coating thickness and absorption enhancement for a given coating refractive index.

Figure $5 \mathrm{~b}$ and c explore the sensitivity of the $E_{\mathrm{Sca}}$ distribution to density and refractive index separately. It is clear that within the range of parameters used, there is greater sensitivity to refractive index than density.

\subsection{Calculating the coating refractive index using the SP-AMS}

In order to convert $E_{\text {Sca }}$ into a physical coating thickness, as described in Sect. 3.5, a coating refractive index must be assumed, in addition to the core density and refractive index. $n_{\mathrm{S}}$ has only a real component at $1064 \mathrm{~nm}$, as any coating material found in the atmosphere is nonabsorbing at this wavelength. Previous studies have assumed a constant value of $n_{\mathrm{S}}$, generally close to 1.5 . We instead used the relative contributions of organics, nitrate and sulfate measured by the SP-AMS to calculate a time-dependent refractive index using volume mixing rules (Stelson, 1990). Nitrate and sulfate were assumed to be associated with ammonium cations as the aerosol in Pasadena was for the most part neutralized (Hayes et al., 2013). Inorganic densities were taken from Weast (1977), and the density of organics was assumed to be $1.2 \mathrm{~g} \mathrm{~cm}^{-3}$, as suggested by Stelson (1990). This density yields a refractive index of organics of 1.46 , which is in the range typically assumed for organics, though it has been shown that oxidation of organics can increase both density (Kroll et al., 2009) and refractive index (Cappa et al., 2011), with opposing effects on scattering calculations. The refractive index for the ambient data calculated with volume mixing was $1.46-1.50$ (mean 1.48). This number is dominated by organics, which formed the bulk of the coating material (we discuss coating composition further in Taylor et al., 2015). Changes were due to variation in the organic/inorganic fractions in ambient aerosol, and clear differences were observed when switching to the thermodenuder.

\subsection{Sources of uncertainty}

Coatings reported for individual particles are subject to both systematic and random errors, whereas average coating properties are subject only to systematic errors as long as enough particles are sampled. As discussed in Sect. S1, the statistical uncertainty in the incandescence signal is $\pm 30 \%$, which corresponds to statistical uncertainty in $D_{\mathrm{C}}$ of ${ }_{-11 \%}^{+9 \%}$. The accuracy of the $\mathrm{rBC}$ mass calibration is $\pm 14 \%$, which corresponds to absolute uncertainty in $D_{\mathrm{C}}$ of ${ }_{-4.9 \%}^{+4.5 \%}$.Calibrations of the optical size of particles using $200 \mathrm{~nm}$ PSLs showed the per-particle uncertainty was $\pm 30 \%$, but increased to $\pm 40 \%$ when using LEO fits due to the decreased signal. After the TEAPD was realigned on 26 May, the modal signal of $200 \mathrm{~nm}$ PSL calibrations throughout the campaign were all within $\pm 3 \%$, demonstrating the stability of the laser power and scattering detectors. The per-particle uncertainty of the scattering and incandescence measurements causes the spread in $E_{\text {Sca }}$ seen in Fig. 5 and, similarly, a width to the distribution of reported coatings.

The uncertainties in the calibration values are due to variation between the mean values of multiple calibrations, and the different instrument response between ambient soot and glassy carbon. These uncertainties represent an estimate of possible systematic errors in the measurements. Other possible systematic uncertainties relate to the core properties $n_{\mathrm{C}}$ and $\rho_{\mathrm{C}}$, which it is the purpose of this paper to investigate, as well as $n_{\mathrm{S}}$, though this sensitivity is thought to be small (Shiraiwa et al., 2008). In Sect. 4.1, we quantify the effect that each of these parameters has on the derived coatings.

The FWHM and notch position have minimal sizedependence for small particles, but for larger particles some variation is expected as these particles take longer to traverse 
the laser beam. However, 200 and $300 \mathrm{~nm}$ PSLs show similar distributions of FWHM and notch position, meaning that for particles $<300 \mathrm{~nm}$ in total diameter (which represent the vast majority of $\mathrm{rBC}$ number) this sensitivity is small. The optical size of particles could be sensitive to the fraction of peak laser power used to generate the LEO fits; however, Laborde et al. (2012) demonstrated that the scattering cross-section of coated particles is stable before they start to evaporate in the laser. As discussed in Sect. 3.3, inspection of single particles showed that $5 \%$ of the peak laser power was within this plateau.

Scattering at $1064 \mathrm{~nm}$ is not thought to be sensitive to particle shape for the sizes of externally mixed particles considered here. For coated rBC particles, shape may affect scattered light intensity but, as we have already discussed, when soot is not in a core / shell configuration the derived coating thicknesses are only a qualitative indicator of mixing state.

We have attempted to minimize and quantify all sources of uncertainty. The sensitivities to the various input parameters are discussed further in Sect. 4.

\section{The effect of core density and refractive index on derived coating thickness}

\subsection{Systematic uncertainties}

Using the coating refractive index calculated from the SPAMS, the absolute and relative coating thicknesses of $\mathrm{BC}$ containing particles were calculated for particles with $\mathrm{rBC}$ core diameter in the range discussed previously in Sect. 3.4. Figure 6 shows the distributions of coating thickness under the same conditions as Fig. 3, using the combinations of core density and refractive index that resulted in the smallest and largest $E_{\text {Sca }}$ in Fig. 5.

Gaussian fits to the least coated distributions yield the single-particle precision. Using a core density $\rho_{\mathrm{C}}=1.8 \mathrm{~g} \mathrm{~cm}^{-3}$ and refractive index $n_{\mathrm{C}}=(2.26-1.26 i)$ generated a distribution of shell/core ratio with mean of 1.04 and standard deviation of 0.21 , corresponding to an absolute coating thickness distribution with mean of $2 \mathrm{~nm}$ and standard deviation of $17 \mathrm{~nm}$. Here, the mean and standard deviation are estimated from Gaussian fits to the data so they are not biased by particles with $E_{\text {Sca }}<1$. For comparison, using a density $\rho_{\mathrm{C}}=2 \mathrm{~g} \mathrm{~cm}^{-3}$ and refractive index $n_{\mathrm{C}}=(1.76-0.44 i)$ generated a distribution of shell / core ratio with mean of 1.40 and standard deviation of 0.19 , corresponding to an absolute coating thickness distribution with mean of $30 \mathrm{~nm}$ and standard deviation of $15 \mathrm{~nm}$. In Fig. 6, the difference in coatings using the different core parameters is larger than the difference between fresh, thermodenuded and aged particles.

The SP2 is capable of measuring a large number of particles rapidly and therefore can obtain data with good counting statistics. The distributions shown in Fig. 6 were generated
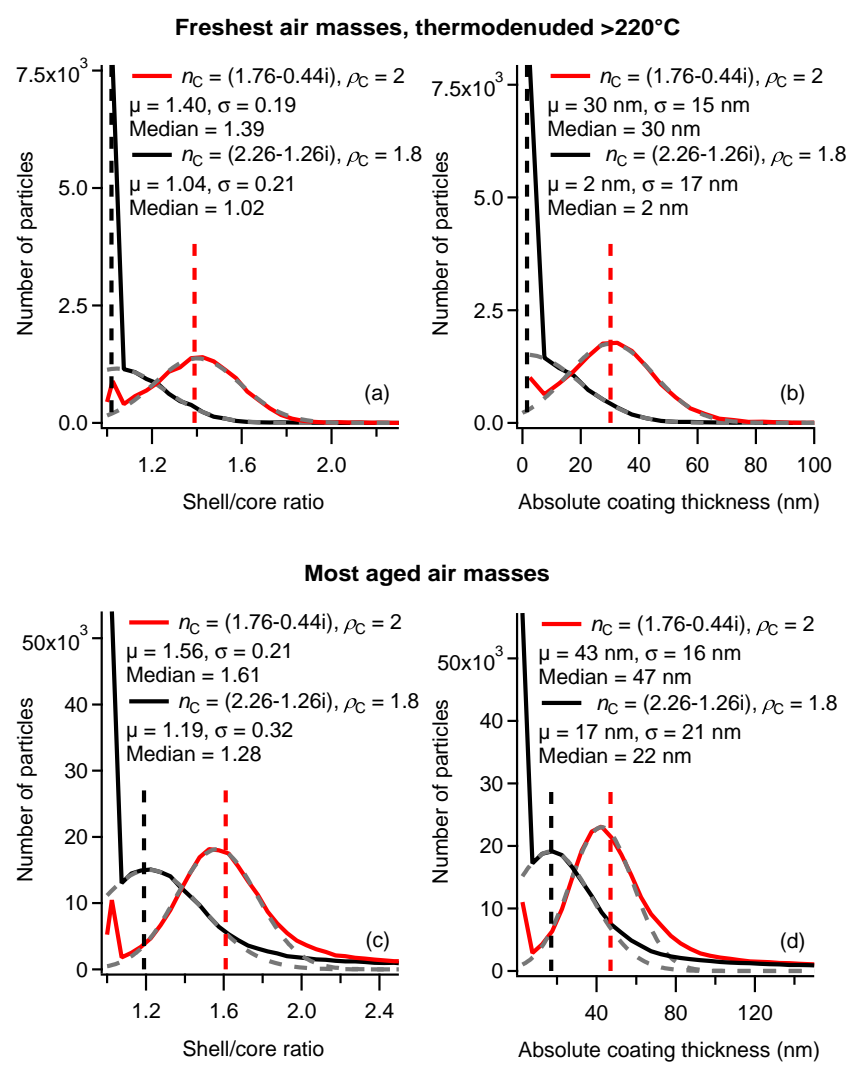

Figure 6. Distributions of (a) and (b) relative and (c) and (d) absolute coating thickness, measured under the same fresh and aged conditions as Fig. 3. The dashed grey lines are Gaussian fits to the primary modes, and fit parameters are listed in the legend. The first bin represents all particles with $E_{\mathrm{Sca}} \leq 1$, and this bin was not used in the Gaussian fits. The vertical dashed lines are the median values, also listed in the legend. These are often used to compare changes in coatings and are only biased by particles with $E_{\mathrm{Sca}}<1$ if the median value falls in this range.

using many thousands of particles. It is most common to use the median values of the properties of the coatings to measure changes in BC mixing state. When taking the median of a sufficient number of particles, the precision of any individual particle becomes unimportant. Only systematic errors can skew the median coating properties.

In order to assess possible systematic uncertainties in the calculated median coatings, we systematically varied each parameter involved in the calculation. The results of these calculations are shown in Table 2. The standard parameters were $n_{\mathrm{C}}=(2.26-1.26 i), \rho_{\mathrm{C}}=1.8 \mathrm{~g} \mathrm{~cm}^{-3}$ and timedependent $n_{\mathrm{S}}$ calculated from the SP-AMS composition data. It is clear by comparing the results of changes in core density and refractive index that the differences in the latter were responsible for the majority of the difference between the red and black traces in Fig. 6. However, by choosing the most appropriate values based on the results of Sect. 3.6, we have, as 
Table 2. Median shell / core ratios and absolute coating thicknesses with varied assumptions about $\rho_{\mathrm{C}}, n_{\mathrm{C}}$ and $n_{\mathrm{S}}$ and varied instrument calibrations. All other parameters were held at their best estimate values, described in the text. For clarity, increasing the scattering calibration refers to increasing the signal of a $200 \mathrm{~nm}$ PSL used to scale the Mie table, whereas increasing the $D_{\mathrm{C}}$ calibration refers to increasing $D_{\mathrm{C}}$.

\begin{tabular}{lllll}
\hline & \multicolumn{2}{c}{ Shell / core ratio } & \multicolumn{2}{c}{ Coating thickness (nm) } \\
& Least coated & Most coated & Least coated & Most coated \\
\hline Best estimate & 1.02 & 1.28 & 2 & 22 \\
\hline$n_{\mathrm{C}}$ & & & & \\
$(2-1 i)$ & 1.12 & 1.39 & 10 & 31 \\
$(1.95-0.79 i)$ & 1.20 & 1.45 & 15 & 35 \\
$(1.87-0.56 i)$ & 1.27 & 1.50 & 22 & 40 \\
$(1.76-0.44 i)$ & 1.33 & 1.54 & 26 & 43 \\
\hline$\rho_{\mathrm{C}}$ & & & & \\
$1.7 \mathrm{~g} \mathrm{~cm}^{-3}$ & 1 & 1.24 & 0 & 19 \\
$1.9 \mathrm{~g} \mathrm{~cm}^{-3}$ & 1.06 & 1.33 & 5 & 25 \\
$2.0 \mathrm{~g} \mathrm{~cm}^{-3}$ & 1.10 & 1.37 & 7 & 23 \\
\hline$n_{\mathrm{S}}$ & & & & 22 \\
1.45 & 1.02 & 1.29 & 2 & 21 \\
1.5 & 1.02 & 1.28 & 2 & 23 \\
1.59 & 1.02 & 1.26 & 1 & \\
\hline Scattering calibration & & & \\
$+3 \%$ & 1.01 & 1.27 & 1 & 22 \\
$-3 \%$ & 1.03 & 1.29 & 2 & \\
\hline$D_{\mathrm{C}}$ calibration & & & & \\
$+4.5 \%$ & 1 & 1.18 & 0 & 23 \\
$-4.9 \%$ & 1.13 & 1.40 & & \\
\hline
\end{tabular}

much as is possible, eliminated this sensitivity as a possible source of systematic error.

Though we have used the SP-AMS composition to calculate a time-dependent $n_{\mathrm{S}}$ to try to eliminate any bias this parameter may have, this measurement is not always available. We therefore performed the same calculations, using $n_{\mathrm{S}}$ of 1.45 and 1.5, which span the range calculated using the SPAMS data, and 1.59, the refractive index of PSLs. The results of these calculations are shown in Table 2. This sensitivity was small - the maximum change was a shift in shell / core of 0.02 (corresponding to $1 \mathrm{~nm}$ absolute coating thickness).

The only systematic uncertainties we were not able to effectively eliminate were the uncertainties associated with the calibration of the core diameter $\left({ }_{-4.9 \%}^{+4.5 \%}\right)$ and the scattering detector $( \pm 3 \%)$. To investigate this uncertainty, we calculated the median coatings using the same particles as those in Fig. 6, but with calibrations 1 standard error away from the mean. Changing the scattering calibration by $\pm 3 \%$ caused a 0.01 shift in median shell / core ratio, and a corresponding $1 \mathrm{~nm}$ shift in coating thickness. Changing the $D_{\mathrm{C}}$ calibration by ${ }_{-4.9 \%}^{+4.5 \%}$ caused a $\sim 0.11$ shift in shell / core ratio, and a corresponding $\sim 8 \mathrm{~nm}$ shift in absolute coating thickness. With the increased $D_{\mathrm{C}}$, the median $E_{\mathrm{Sca}}$ was 0.81 , but the coatings were assigned to that of externally mixed particles. When combining this value with the scattering uncertainty in quadrature, the scattering uncertainty is insignificant, and the systematic uncertainty associated with the instrument calibration is the same as the uncertainty associated with the $D_{\mathrm{C}}$ calibration.

In the least coated conditions, the median measured shell / core ratio was $1.02 \pm 0.11$, corresponding to an absolute coating thickness of $2 \pm 8 \mathrm{~nm}$. The proximity of this result to externally mixed soot demonstrates that when using these parameters for density and refractive index, this technique can accurately determine the median mixing state (externally vs. internally mixed) of ambient BC-containing particles within the precision of the instrument calibration. We note however that the precision will depend on the specific setup of the instrument (e.g. alignment, detector gain settings). If used with different $\rho_{\mathrm{C}}$ and $n_{\mathrm{C}}$ the precision is similar, as is the uncertainty associated with the instrument calibrations, but the average values would not be accurate for ambient soot. Using the same least-coated measured data, but assuming $\rho_{\mathrm{C}}=2 \mathrm{~g} \mathrm{~cm}^{-3}$ and refractive index $n_{\mathrm{C}}=$ (1.76-0.44i), the median shell / core ratio was $1.39 \pm 0.11$, and absolute coating thickness $30 \pm 8 \mathrm{~nm}$. Here the uncertainties are those associated with the instrument calibration, but they do not represent the systematic uncertainty due to the use of the different values for $\rho_{\mathrm{C}}$ and $n_{\mathrm{C}}$. The uncertainty 


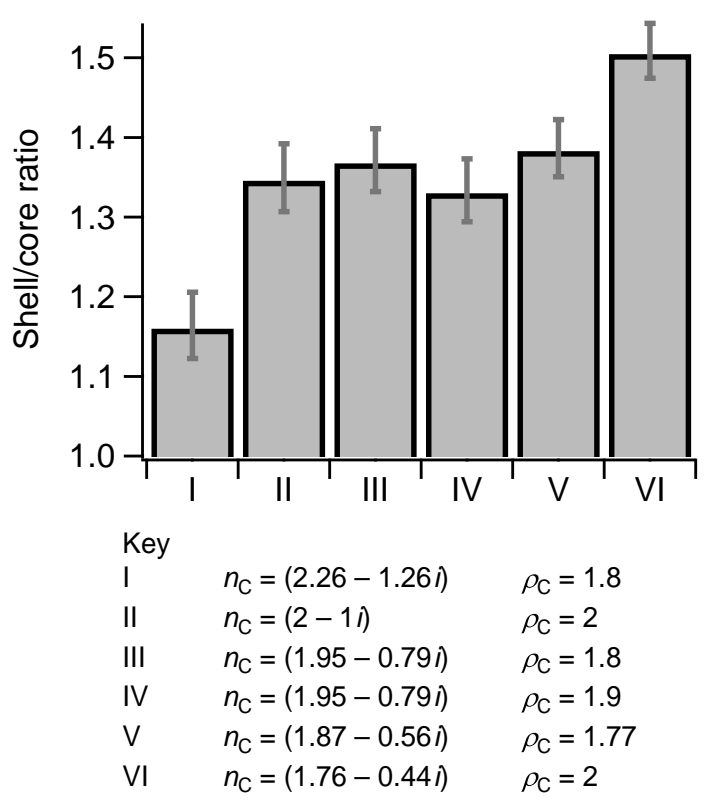

Figure 7. Sensitivity of variation in ambient median shell / core ratio to $\mathrm{rBC}$ core refractive index and density, listed in units of $\mathrm{g} \mathrm{cm}^{-3}$. Data shown are the medians of each $5 \mathrm{~min}$ period throughout the campaign, with error bars for the 25 th and 75 th percentiles.

associated with the core refractive index is larger than any of the other sensitivities listed in Table 2.

\subsection{Time-dependent variation}

Figure 7 shows the effect of systematic offsets associated with the use of different $n_{\mathrm{C}}$ and $\rho_{\mathrm{C}}$ on the measured shell / core ratios over the whole campaign. The density and refractive index recommended by Moteki et al. (2010) were shown in Sect. 3.6 to be the most appropriate for this data set and result in the lowest coating thicknesses. This result emphasizes that comparisons between different data sets can show differences that can be significantly influenced by the choice of core parameters and misrepresent any underlying similarity or difference between the data sets.

While the use of different core density and refractive index values may systematically change reported coating parameters, there is also variation in coatings due to real changes in the ambient particles. Figure 8 compares changes in the median shell / core ratio, using the refractive index and density combinations that result in the thickest and thinnest coatings, as a function of photochemical ageing. Changes in coatings were captured regardless of the parameters used, but there was a significant offset between the data using the different sets of density and refractive index of the $\mathrm{rBC}$ core. The difference between the minimum and maximum coating thicknesses reported does have a dependence on these parameters, but this range is small compared to the difference in the absolute values. When using the density and refractive index recommended by Moteki et al. (2010), in the

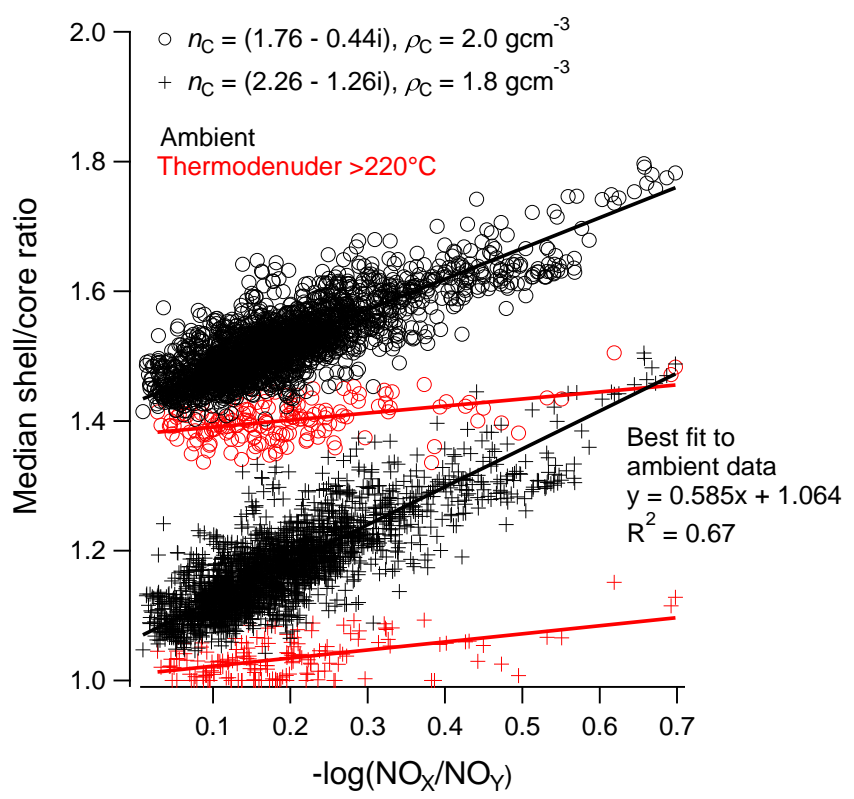

Figure 8. Median shell/core ratio for particles with $135 \leq$ $D_{\mathrm{C}} \leq 200 \mathrm{~nm}$ plotted vs. ambient $-\log \left(\mathrm{NO}_{\mathrm{x}} / \mathrm{NO}_{\mathrm{y}}\right)$. Data are plotted for the sets of core refractive index and density that result in the thickest and thinnest coatings. Both ambient and thermodenuded $\left(>220^{\circ} \mathrm{C}\right)$ data are shown. The straight lines are linear orthogonal distance regression fits to the data. By definition, the minimum measurable shell / core ratio is 1 .

most coated conditions of Fig. 6, the median shell / core ratio was $1.28 \pm 0.11$, though there were some data periods in Fig. 8 with values up to $\sim 1.5 \pm 0.11$. These values are several times larger than the systematic uncertainty associated with the instrument calibration, meaning that the SP2 is able to resolve absolute differences in mixing state, though for coated particles there may also be an additional uncertainty associated with the morphology of internally mixed soot particles (Liu et al., 2015).

Coatings were thickest in the most processed air masses, similar to results reported from urban plumes in the western Pacific (Moteki et al., 2007; Shiraiwa et al., 2007) and in California, including some in the Los Angeles area (Sahu et al., 2012). It has consistently been observed that, in regions where secondary aerosols also constitute a large fraction of submicron particulate matter, condensation of secondary material increases BC coating thicknesses with age. Even using the core parameters that result in the thinnest coatings, the freshest ambient BC-containing particles were also associated with some coating material.

Coatings measured through the thermodenuder were thinner than ambient coatings, though this difference was smallest in the least processed air masses as the ambient particles were less internally mixed. When the core parameters that result in the thickest coatings were applied, even the thermodenuded particles appeared to have significant coating material. 
Taking these data in isolation could therefore lead to misleading conclusions about the optical properties of $\mathrm{BC}$ and its CCN activity. This potential bias must be considered if $\mathrm{BC}$ coating data generated in this way are to be used quantitatively.

\section{Conclusions}

We have demonstrated that coating properties of black carbon particles derived by core / shell modelling of SP2 data show a strong sensitivity to the assumed parameters of the $\mathrm{rBC}$ core. For a given measured scattering signal and core mass, a higher refractive index (real and imaginary) and lower core density result in a larger scattering cross-section due to the core, meaning less scattering is attributed to a coating. This shift results in thinner calculated coating thicknesses for the same measurement data.

An assessment of the coating properties of freshly emitted, thermodenuded ambient particles demonstrated that, when using the appropriate core density and refractive index, the SP2 incandescence/scattering technique can accurately determine the mixing state (externally or internally mixed) of ambient $\mathrm{rBC}$ within the precision of the instrument calibration. Using a core density of $1.8 \mathrm{~g} \mathrm{~cm}^{-3}$ (Bond and Bergstrom, 2006) and refractive index of (2.26-1.26i) (Moteki et al., 2010) generated a distribution with median shell / core ratio of $1.02 \pm 0.11$ corresponding to an absolute coating thickness of $2 \pm 8 \mathrm{~nm}$. The main source of statistical error in the measurement of single particles was random variation of the incandescence measurement. Other than the sensitivity to core refractive index, the incandescence calibration was the main source of uncertainty in the average coatings. The refractive index of coatings was found to have only a minor influence. On the newer D-series SP2 the single-particle precision may be improved by the higher resolution, but the systematic error on the median coating properties can only be improved with a more accurate incandescence calibration.

The effective density of soot particles is subject to considerable variability due to complex, varying soot morphology in different atmospheric conditions. However, at a nearinfrared wavelength of $1064 \mathrm{~nm}$, light scattering is less sensitive to the particle geometry as the wavelength is large compared to the measured size of $\mathrm{rBC}$. The bulk density of black carbon of $1.8 \mathrm{~g} \mathrm{~cm}^{-3}$ as suggested by Bond and Bergstrom (2006) is appropriate to derive the $\mathrm{rBC}$ volume based on the direct mass measurement from the SP2. However, the use of the bulk density may not be appropriate at visible wavelengths, where shape has much more of an influence on optical properties. The core refractive index measured using the SP2 (Moteki et al., 2010) is larger than that recommended by Bond and Bergstrom (2006) for use at visible wavelengths. The wavelength-dependence of black carbon's refractive index is highly uncertain, and caution should be taken when using this value of $\mathrm{BC}$ refractive index for optical calculations at different wavelengths.

The use of different core parameters caused a systematic difference in the reported coating data. The majority of these differences were due to the change in the refractive index of the core. Calculations performed using the same measured data but with the core parameters that resulted in the thickest coatings generated a median shell / core ratio of $1.39 \pm 0.11$, corresponding to an absolute coating thickness of $30 \pm 8 \mathrm{~nm}$. Here, the quoted errors are due to the instrument calibration, and do not capture the systematic uncertainty associated with the use of the different core refractive index and density.

Temporal changes in coating thickness were also measured, which were several times larger than the uncertainty associated with the instrument calibration. Coatings were thickest in the most processed air masses. This change is similar to previous results from California and the western Pacific, where a large fraction of submicron aerosol is also secondary, and suggests a consistent picture of increased coating by condensation of secondary aerosol. While these relative changes in coating thickness were captured well regardless of the density and refractive index used in the Mie model, the sensitivity to assumed core properties must be taken into account when comparing different data sets or when using SP2 coating data to compare with large-scale models. Omitting information of this sensitivity could lead to misleading conclusions regarding the optical properties of $\mathrm{BC}$ and its CCN activity.

We have determined the most appropriate values of $\mathrm{BC}$ density and refractive index to use to measure mixing state at $1064 \mathrm{~nm}$ where particle morphology has only a minor effect, but appropriate values to use for optical calculations of nonspherical particles at visible wavelengths may be different. At present, there are significant uncertainties in the absolute values of the refractive index and density of $\mathrm{BC}$ particles. Without similar constraints as those provided here, constraining the behaviour of $\mathrm{BC}$ particles in models using field data will be subject to large systematic measurement uncertainties.

\section{The Supplement related to this article is available online at doi:10.5194/amt-8-1701-2015-supplement.}

Acknowledgements. The authors thank J. Jimenez, J. Stutz, J. de Gouw and J. Seinfeld for co-organizing the CalNex-LA site in Pasadena, and the California Air Resources Board and California Institute of Technology for providing funding and logistic support for the ground-site. We thank K. Froyd, S. M. Murphy and D. Murphy for the setup and use of their sampling inlet and DMA, J. Smith for the loan of the thermodenuder and P. Chhabra for logistical support. We thank P. Zeiger, M. Gysel and J. Crosier for their technical assistance in generating the Mie look-up tables, and 
J. Schwarz and A. Perring for useful discussions. The University of Manchester activities were supported by The UK Natural Environment Research Council through a PhD studentship and the project Multiscale Chemical Composition of Carbonaceous particles and Coatings (MC4) [Grant ref: NE/H008136/1]. Processed data are available on the CalNex data archive. Raw data are archived at the University of Manchester and available on request.

Edited by: J. Joiner

\section{References}

Adachi, K. and Buseck, P. R.: Changes of ns-soot mixing states and shapes in an urban area during CalNex, J. Geophys. Res. Atmos., 118, 3723-3730, doi:10.1002/jgrd.50321, 2013.

Adachi, K., Chung, S. H., and Buseck, P. R.: Shapes of soot aerosol particles and implications for their effects on climate, J. Geophys. Res., 115, D15206, doi:10.1029/2009jd012868, 2010.

Allan, J. D., Delia, A. E., Coe, H., Bower, K. N., Alfarra, M. R., Jimenez, J. L., Middlebrook, A. M., Drewnick, F., Onasch, T. B., Canagaratna, M. R., Jayne, J. T., and Worsnop, D. R.: A generalised method for the extraction of chemically resolved mass spectra from Aerodyne aerosol mass spectrometer data, J. Aerosol Sci., 35, 909-922, doi:10.1016/j.jaerosci.2004.02.007, 2004.

Bahreini, R., Middlebrook, A. M., de Gouw, J. A., Warneke, C., Trainer, M., Brock, C. A., Stark, H., Brown, S. S., Dube, W. P., Gilman, J. B., Hall, K., Holloway, J. S., Kuster, W. C., Perring, A. E., Prevot, A. S. H., Schwarz, J. P., Spackman, J. R., Szidat, S., Wagner, N. L., Weber, R. J., Zotter, P., and Parrish, D.: Gasoline emissions dominate over diesel in formation of secondary organic aerosol mass, Geophys. Res. Lett., 39, L06805, doi:10.1029/2011g1050718, 2012.

Bohren, C. F. and Huffman, D. R.: Absorption and scattering of light by small particles, Wiley, New York, 1983.

Bond, T. C. and Bergstrom, R. W.: Light absorption by carbonaceous particles: An investigative review, Aerosol Sci. Technol., 40, 27-67, doi:10.1080/02786820500421521, 2006.

Bond, T. C. and Sun, H. L.: Can reducing black carbon emissions counteract global warming?, Environ. Sci. Technol., 39, 59215926, doi:10.1021/es0480421, 2005.

Bond, T. C., Doherty, S. J., Fahey, D. W., Forster, P. M., Berntsen, T., DeAngelo, B. J., Flanner, M. G., Ghan, S., Kärcher, B., Koch, D., Kinne, S., Kondo, Y., Quinn, P. K., Sarofim, M. C., Schultz, M. G., Schulz, M., Venkataraman, C., Zhang, H., Zhang, S., Bellouin, N., Guttikunda, S. K., Hopke, P. K., Jacobson, M. Z., Kaiser, J. W., Klimont, Z., Lohmann, U., Schwarz, J. P., Shindell, D., Storelvmo, T., Warren, S. G., and Zender, C. S.: Bounding the role of black carbon in the climate system: A scientific assessment, J. Geophys. Res.-Atmos., 118, 1-173, doi:10.1002/jgrd.50171, 2013.

Cappa, C. D., Che, D. L., Kessler, S. H., Kroll, J. H., and Wilson, K. R.: Variations in organic aerosol optical and hygroscopic properties upon heterogeneous $\mathrm{OH}$ oxidation, J. Geophys. Res., 116, D15204, doi:10.1029/2011jd015918, 2011.

Cappa, C. D., Onasch, T. B., Massoli, P., Worsnop, D. R., Bates, T. S., Cross, E. S., Davidovits, P., Hakala, J., Hayden, K. L., Jobson, B. T., Kolesar, K. R., Lack, D. A., Lerner, B. M., Li,
S.-M., Mellon, D., Nuaaman, I., Olfert, J. S., Petaja, T., Quinn, P. K., Song, C., Subramanian, R., Williams, E. J., and Zaveri, R. A.: Radiative Absorption Enhancements Due to the Mixing State of Atmospheric Black Carbon, Science, 337, 1078-1081, doi:10.1126/science.1223447, 2012.

Cappa, C. D., Onasch, T. B., Massoli, P., Worsnop, D. R., Bates, T. S., Cross, E. S., Davidovits, P., Hakala, J., Hayden, K. L., Jobson, B. T., Kolesar, K. R., Lack, D. A., Lerner, B. M., Li, S.-M., Mellon, D., Nuaaman, I., Olfert, J. S., Petaja, T., Quinn, P. K., Song, C., Subramanian, R., Williams, E. J., and Zaveri, R. A.: Response to Comment on "Radiative Absorption Enhancements Due to the Mixing State of Atmospheric Black Carbon", Science, 339, 393-393, doi:10.1126/science.1230260, 2013.

Cross, E. S., Onasch, T. B., Ahern, A., Wrobel, W., Slowik, J. G., Olfert, J., Lack, D. A., Massoli, P., Cappa, C. D., Schwarz, J. P., Spackman, J. R., Fahey, D. W., Sedlacek, A., Trimborn, A., Jayne, J. T., Freedman, A., Williams, L. R., Ng, N. L., Mazzoleni, C., Dubey, M., Brem, B., Kok, G., Subramanian, R., Freitag, S., Clarke, A., Thornhill, D., Marr, L. C., Kolb, C. E., Worsnop, D. R., and Davidovits, P.: Soot Particle StudiesInstrument InterComparisonProject Overview, Aerosol Sci. Technol., 44, 592611, doi:10.1080/02786826.2010.482113, 2010.

DeCarlo, P. F., Kimmel, J. R., Trimborn, A., Northway, M. J., Jayne, J. T., Aiken, A. C., Gonin, M., Fuhrer, K., Horvath, T., Docherty, K. S., Worsnop, D. R., and Jimenez, J. L.: Field-deployable, high-resolution, time-of-flight aerosol mass spectrometer, Anal. Chem., 78, 8281-8289, doi:10.1021/ac061249n, 2006.

Fuentes, E. and McFiggans, G.: A modeling approach to evaluate the uncertainty in estimating the evaporation behaviour and volatility of organic aerosols, Atmos. Meas. Tech., 5, 735-757, doi:10.5194/amt-5-735-2012, 2012.

Gao, R. S., Schwarz, J. P., Kelly, K. K., Fahey, D. W., Watts, L. A., Thompson, T. L., Spackman, J. R., Slowik, J. G., Cross, E. S., Han, J.-H. H., Davidovits, P., Onasch, T. B., and Worsnop, D. R.: A Novel Method for Estimating LightScattering Properties of Soot Aerosols Using a Modified SingleParticle Soot Photometer, Aerosol Sci. Technol., 41, 125-135, doi:10.1080/02786820601118398, 2007.

Gao, R. S., Hall, S. R., Swartz, W. H., Schwarz, J. P., Spackman, J. R., Watts, L. A., Fahey, D. W., Aikin, K. C., Shetter, R. E., and Bui, T. P.: Calculations of solar shortwave heating rates due to black carbon and ozone absorption using in situ measurements, J. Geophys. Res., 113, D14203, doi:10.1029/2007jd009358, 2008.

Ghazi, R. and Olfert, J. S.: Coating Mass Dependence of Soot Aggregate Restructuring due to Coatings of Oleic Acid and Dioctyl Sebacate, Aerosol Sci. Technol., 47, 192-200, doi:10.1080/02786826.2012.741273, 2013.

Hayes, P. L., Ortega, A. M., Cubison, M. J., Froyd, K. D., Zhao, Y., Cliff, S. S., Hu, W. W., Toohey, D. W., Flynn, J. H., Lefer, B. L., Grossberg, N., Alvarez, S., Rappenglück, B., Taylor, J. W., Allan, J. D., Holloway, J. S., Gilman, J. B., Kuster, W. C., de Gouw, J. A., Massoli, P., Zhang, X., Liu, J., Weber, R. J., Corrigan, A. L., Russell, L. M., Isaacman, G., Worton, D. R., Kreisberg, N. M., Goldstein, A. H., Thalman, R., Waxman, E. M., Volkamer, R., Lin, Y. H., Surratt, J. D., Kleindienst, T. E., Offenberg, J. H., Dusanter, S., Griffith, S., Stevens, P. S., Brioude, J., Angevine, W. M., and Jimenez, J. L.: Organic aerosol composition and sources in Pasadena, California, during the 2010 
CalNex campaign, J. Geophys. Res.-Atmos., 118, 9233-9257, doi:10.1002/jgrd.50530, 2013.

Hess, M., Koepke, P., and Schult, I.: Optical properties of aerosols and clouds: The software package OPAC, B. Am. Meteorol. Soc., 79, 831-844, doi:10.1175/15200477(1998)079<0831:opoaac>2.0.co;2, 1998.

Huang, X. F., Gao, R. S., Schwarz, J. P., He, L. Y., Fahey, D. W., Watts, L. A., McComiskey, A., Cooper, O. R., Sun, T. L., Zeng, L. W., Hu, M., and Zhang, Y. H.: Black carbon measurements in the Pearl River Delta region of China, J. Geophys. Res., 116, D12208, doi:10.1029/2010jd014933, 2011.

Huffman, J. A., Ziemann, P. J., Jayne, J. T., Worsnop, D. R., and Jimenez, J. L.: Development and characterization of a fast-stepping/scanning thermodenuder for chemically-resolved aerosol volatility measurements, Aerosol Sci. Technol., 42, 395407, doi:10.1080/02786820802104981, 2008.

Jacobson, M. Z.: Control of fossil-fuel particulate black carbon and organic matter, possibly the most effective method of slowing global warming, J. Geophys. Res., 107, 4410, doi:10.1029/2001JD001376, 2002.

Jacobson, M. Z.: Short-term effects of controlling fossil-fuel soot, biofuel soot and gases, and methane on climate, Arctic ice, and air pollution health, J. Geophys. Res., 115, D14209, doi:10.1029/2009JD013795, 2010.

Janssen, N. A. H., Gerlofs-Nijland, M. E., Lanki, T., Salonen, R. O., Cassee, F., Hoek, G., Fischer, P., Brunekreef, B., and Krzyzanowski, M.: Health effects of black carbon, edited by: Bohr, R., World Health Organisation, Copenhagen, Denmark, 2012.

Kahnert, M., Nousiainen, T., Lindqvist, H., and Ebert, M.: Optical properties of light absorbing carbon aggregates mixed with sulfate: assessment of different model geometries for climate forcing calculations, Opt. Express, 20, 10042-10058, doi:10.1364/oe.20.010042, 2012.

Khalizov, A. F., Zhang, R., Zhang, D., Xue, H., Pagels, J., and McMurry, P. H.: Formation of highly hygroscopic soot aerosols upon internal mixing with sulfuric acid vapor, J. Geophys. Res., 114, D05208, doi:10.1029/2008JD010595, 2009.

Kleinman, L. I., Daum, P. H., Lee, Y.-N., Senum, G. I., Springston, S. R., Wang, J., Berkowitz, C., Hubbe, J., Zaveri, R. A., Brechtel, F. J., Jayne, J., Onasch, T. B., and Worsnop, D.: Aircraft observations of aerosol composition and ageing in New England and Mid-Atlantic States during the summer 2002 New England Air Quality Study field campaign, J. Geophys. Res., 112, D09310, doi:10.1029/2006jd007786, 2007.

Kondo, Y., Matsui, H., Moteki, N., Sahu, L., Takegawa, N., Kajino, M., Zhao, Y., Cubison, M. J., Jimenez, J. L., Vay, S., Diskin, G. S., Anderson, B., Wisthaler, A., Mikoviny, T., Fuelberg, H. E., Blake, D. R., Huey, G., Weinheimer, A. J., Knapp, D. J., and Brune, W. H.: Emissions of black carbon, organic, and inorganic aerosols from biomass burning in North America and Asia in 2008, J. Geophys. Res., 116, D08204, doi:10.1029/2010JD015152, 2011a.

Kondo, Y., Sahu, L., Moteki, N., Khan, F., Takegawa, N., Liu, X., Koike, M., and Miyakawa, T.: Consistency and Traceability of Black Carbon Measurements Made by Laser-Induced Incandescence, Thermal-Optical Transmittance, and Filter-Based Photo-Absorption Techniques, Aerosol Sci. Technol., 45, 295312, doi:10.1080/02786826.2010.533215, $2011 \mathrm{~b}$.
Kroll, J. H., Smith, J. D., Che, D. L., Kessler, S. H., Worsnop, D. R., and Wilson, K. R.: Measurement of fragmentation and functionalization pathways in the heterogeneous oxidation of oxidized organic aerosol, Phys. Chem. Chem. Phys., 11, 8005-8014, doi:10.1039/b905289e, 2009.

Laborde, M., Mertes, P., Zieger, P., Dommen, J., Baltensperger, U., and Gysel, M.: Sensitivity of the Single Particle Soot Photometer to different black carbon types, Atmos. Meas. Tech., 5, 10311043, doi:10.5194/amt-5-1031-2012, 2012.

Laborde, M., Crippa, M., Tritscher, T., Jurányi, Z., Decarlo, P. F., Temime-Roussel, B., Marchand, N., Eckhardt, S., Stohl, A., Baltensperger, U., Prévôt, A. S. H., Weingartner, E., and Gysel, M.: Black carbon physical properties and mixing state in the European megacity Paris, Atmos. Chem. Phys., 13, 5831-5856, doi:10.5194/acp-13-5831-2013, 2013.

Lack, D. A., Langridge, J. M., Bahreini, R., Cappa, C. D., Middlebrook, A. M., and Schwarz, J. P.: Brown carbon and internal mixing in biomass burning particles., P. Natl. Acad. Sci. USA, 109, 14802-14807, doi:10.1073/pnas.1206575109, 2012.

Langridge, J. M., Lack, D., Brock, C. A., Bahreini, R., Middlebrook, A. M., Neuman, J. A., Nowak, J. B., Perring, A. E., Schwarz, J. P., Spackman, J. R., Holloway, J. S., Pollack, I. B., Ryerson, T. B., Roberts, J. M., Warneke, C., de Gouw, J. A., Trainer, M. K., and Murphy, D. M.: Evolution of aerosol properties impacting visibility and direct climate forcing in an ammonia-rich urban environment, J. Geophys. Res., 117, D00V11, doi:10.1029/2011jd017116, 2012.

Lefer, B., Rappenglueck, B., Flynn, J., and Haman, C.: Photochemical and meteorological relationships during the Texas-II Radical and Aerosol Measurement Project (TRAMP), Atmos. Environ., 44, 4005-4013, doi:10.1016/j.atmosenv.2010.03.011, 2010.

Liu, D., Flynn, M., Gysel, M., Targino, A., Crawford, I., Bower, K., Choularton, T., Jurányi, Z., Steinbacher, M., Hüglin, C., Curtius, J., Kampus, M., Petzold, A., Weingartner, E., Baltensperger, U., and Coe, H.: Single particle characterization of black carbon aerosols at a tropospheric alpine site in Switzerland, Atmos. Chem. Phys., 10, 7389-7407, doi:10.5194/acp-10-73892010, 2010.

Liu, D., Taylor, J. W., Young, D. E., Flynn, M. J., Coe, H., and Allan, J. D.: The effect of complex black carbon microphysics on the determination of the optical properties of brown carbon, Geophys. Res. Lett., 42, 613-619, doi:10.1002/2014GL062443, 2015.

Liu, L., Mishchenko, M. I., and Arnott, W. P.: A study of radiative properties of fractal soot aggregates using the superposition Tmatrix method, J. Quant. Spectrosc. Radiat. Transf., 109, 26562663, doi:10.1016/j.jqsrt.2008.05.001, 2008.

Luke, W. T., Kelley, P., Lefer, B. L., Flynn, J., Rappenglueck, B., Leuchner, M., Dibb, J. E., Ziemba, L. D., Anderson, C. H., and Buhr, M.: Measurements of primary trace gases and $\mathrm{NO}_{\mathrm{y}}$ composition in Houston, Texas, Atmos. Environ., 44, 4068-4080, doi:10.1016/j.atmosenv.2009.08.014, 2010.

Marley, N. A., Gaffney, J. S., Baird, C., Blazer, C. A., Drayton, P. J., and Frederick, J. E.: An empirical method for the determination of the complex refractive index of size-fractionated atmospheric aerosols for radiative transfer calculations, Aerosol Sci. Technol., 34, 535-549, doi:10.1080/02786820118599, 2001.

Matsui, H., Koike, M., Kondo, Y., Moteki, N., Fast, J. D., and Zaveri, R. A.: Development and validation of a black carbon 
mixing state resolved three-dimensional model: Aging processes and radiative impact, J. Geophys. Res.-Atmos., 118, 2304-2326, doi:10.1029/2012JD018446, 2013.

McMeeking, G. R., Hamburger, T., Liu, D., Flynn, M., Morgan, W. T., Northway, M., Highwood, E. J., Krejci, R., Allan, J. D., Minikin, A., and Coe, H.: Black carbon measurements in the boundary layer over western and northern Europe, Atmos. Chem. Phys., 10, 9393-9414, doi:10.5194/acp-10-9393-2010, 2010.

Metcalf, A. R., Craven, J. S., Ensberg, J. J., Brioude, J., Angevine, W., Sorooshian, A., Duong, H. T., Jonsson, H. H., Flagan, R. C., and Seinfeld, J. H.: Black carbon aerosol over the Los Angeles Basin during CalNex, J. Geophys. Res., 117, D00V13, doi:10.1029/2011jd017255, 2012.

Moteki, N. and Kondo, Y.: Effects of mixing state on black carbon measurements by laser-induced incandescence, Aerosol Sci. Technol., 41, 398-417, doi:10.1080/02786820701199728, 2007.

Moteki, N. and Kondo, Y.: Method to measure time-dependent scattering cross sections of particles evaporating in a laser beam, J. Aerosol Sci., 39, 348-364 doi:10.1016/j.jaerosci.2007.12.002, 2008.

Moteki, N., Kondo, Y., Miyazaki, Y., Takegawa, N., Komazaki, Y., Kurata, G., Shirai, T., Blake, D. R., Miyakawa, T., and Koike, M.: Evolution of mixing state of black carbon particles: Aircraft measurements over the western Pacific in March 2004, Geophys. Res. Lett., 34, L11803, doi:10.1029/2006g1028943, 2007.

Moteki, N., Kondo, Y., and Nakamura, S.: Method to measure refractive indices of small nonspherical particles: Application to black carbon particles, J. Aerosol Sci., 41, 513-521, doi:10.1016/j.jaerosci.2010.02.013, 2010.

Moteki, N., Kondo, Y., Oshima, N., Takegawa, N., Koike, M., Kita, K., Matsui, H., and Kajino, M.: Size dependence of wet removal of black carbon aerosols during transport from the boundary layer to the free troposphere, Geophys. Res. Lett., 39, L13802, doi:10.1029/2012GL052034, 2012.

Onasch, T. B., Trimborn, A., Fortner, E. C., Jayne, J. T., Kok, G. L., Williams, L. R., Davidovits, P., and Worsnop, D. R.: Soot Particle Aerosol Mass Spectrometer: Development, Validation, and Initial Application, Aerosol Sci. Technol., 46, 804-817, doi:10.1080/02786826.2012.663948, 2012.

Park, K., Kittelson, D. B., Zachariah, M. R., and McMurry, P. H.: Measurement of inherent material density of nanoparticle agglomerates, J. Nanoparticle Res., 6, 267-272, doi:10.1023/B:NANO.0000034657.71309.e6, 2004.

Pena, O. and Pal, U.: Scattering of electromagnetic radiation by a multilayered sphere, Comput. Phys. Commun., 180, 2348-2354, doi:10.1016/j.cpc.2009.07.010, 2009.

Petzold, A., Ogren, J. A., Fiebig, M., Laj, P., Li, S.-M., Baltensperger, U., Holzer-Popp, T., Kinne, S., Pappalardo, G., Sugimoto, N., Wehrli, C., Wiedensohler, A., and Zhang, X.-Y.: Recommendations for reporting "black carbon" measurements, Atmos. Chem. Phys., 13, 8365-8379, doi:10.5194/acp-13-83652013, 2013.

Ramanathan, V. and Carmichael, G.: Global and regional climate changes due to black carbon, Nat. Geosci., 1, 221-227, doi:10.1038/ngeo156, 2008.

Ryerson, T. B., Andrews, A. E., Angevine, W. M., Bates, T. S., Brock, C. A., Cairns, B., Cohen, R. C., Cooper, O. R., de Gouw, J. A., Fehsenfeld, F. C., Ferrare, R. A., Fischer, M. L., Flagan, R. C., Goldstein, A. H., Hair, J. W., Hardesty, R. M., Hostetler, C.
A., Jimenez, J. L., Langford, A. O., McCauley, E., McKeen, S. A., Molina, L. T., Nenes, A., Oltmans, S. J., Parrish, D. D., Pederson, J. R., Pierce, R. B., Prather, K., Quinn, P. K., Seinfeld, J. H., Senff, C. J., Sorooshian, A., Stutz, J., Surratt, J. D., Trainer, M., Volkamer, R., Williams, E. J., and Wofsy, S. C.: The 2010 California Research at the Nexus of Air Quality and Climate Change (CalNex) field study, J. Geophys. Res.-Atmos., 118, 5830-5866, doi:10.1002/jgrd.50331, 2013.

Sahu, L. K., Kondo, Y., Moteki, N., Takegawa, N., Zhao, Y., Cubison, M. J., Jimenez, J. L., Vay, S., Diskin, G. S., Wisthaler, A., Mikoviny, T., Huey, L. G., Weinheimer, A. J., and Knapp, D. J.: Emission characteristics of black carbon in anthropogenic and biomass burning plumes over California during ARCTAS-CARB 2008, J. Geophys. Res., 117, D16302, doi:10.1029/2011JD017401, 2012.

Schnaiter, M., Linke, C., Mohler, O., Naumann, K. H., Saathoff, H., Wagner, R., Schurath, U., and Wehner, B.: Absorption amplification of black carbon internally mixed with secondary organic aerosol, J. Geophys. Res., 110, D19204, doi:10.1029/2005jd006046, 2005.

Schwarz, J. P., Gao, R. S., Spackman, J. R., Watts, L. A., Thomson, D. S., Fahey, D. W., Ryerson, T. B., Peischl, J., Holloway, J. S., Trainer, M., Frost, G. J., Baynard, T., Lack, D. A., de Gouw, J. A., Warneke, C., and Del Negro, L. A.: Measurement of the mixing state, mass, and optical size of individual black carbon particles in urban and biomass burning emissions, Geophys. Res. Lett., 35, L13810, doi:10.1029/2008GL033968, 2008a.

Schwarz, J. P., Spackman, J. R., Fahey, D. W., Gao, R. S., Lohmann, U., Stier, P., Watts, L. A., Thomson, D. S., Lack, D. A., Pfister, L., Mahoney, M. J., Baumgardner, D., Wilson, J. C., and Reeves, J. M.: Coatings and their enhancement of black carbon light absorption in the tropical atmosphere, J. Geophys. Res., 113, D03203, doi:10.1029/2007jd009042, 2008b.

Schwarz, J. P., Stark, H., Spackman, J. R., Ryerson, T. B., Peischl, J., Swartz, W. H., Gao, R. S., Watts, L. A., and Fahey, D. W.: Heating rates and surface dimming due to black carbon aerosol absorption associated with a major US city, Geophys. Res. Lett., 36, L15807, doi:10.1029/2009g1039213, 2009.

Schwarz, J. P., Spackman, J. R., Gao, R. S., Perring, A. E., Cross, E., Onasch, T. B., Ahern, A., Wrobel, W., Davidovits, P., Olfert, J., Dubey, M. K., Mazzoleni, C., and Fahey, D. W.: The Detection Efficiency of the Single Particle Soot Photometer, Aerosol Sci. Technol., 44, 612-628, doi:10.1080/02786826.2010.481298, 2010.

Shiraiwa, M., Kondo, Y., Moteki, N., Takegawa, N., Miyazaki, Y., and Blake, D. R.: Evolution of mixing state of black carbon in polluted air from Tokyo, Geophys. Res. Lett., 34, L16803, doi:10.1029/2007g1029819, 2007.

Shiraiwa, M., Kondo, Y., Moteki, N., Takegawa, N., Sahu, L. K., Takami, A., Hatakeyama, S., Yonemura, S., and Blake, D. R.: Radiative impact of mixing state of black carbon aerosol in Asian outflow, J. Geophys. Res., 113, D24210, doi:10.1029/2008jd010546, 2008.

Shiraiwa, M., Kondo, Y., Iwamoto, T., and Kita, K.: Amplification of Light Absorption of Black Carbon by Organic Coating, Aerosol Sci. Technol., 44, 46-54, doi:10.1080/02786820903357686, 2010.

Slowik, J. G., Cross, E. S., Han, J. H., Davidovits, P., Onasch, T. B., Jayne, J. T., Williams, L. R., Canagaratna, M. R., Worsnop, D. 
R., Chakrabarty, R. K., Moosmuller, H., Arnott, W. P., Schwarz, J. P., Gao, R. S., Fahey, D. W., Kok, G. L., and Petzold, A.: An inter-comparison of instruments measuring black carbon content of soot particles, Aerosol Sci. Technol., 41, 295-314, doi:10.1080/02786820701197078, 2007.

Stelson, A. W.: Urban aerosol refractive-index prediction by partial molar refraction approach, Environ. Sci. Technol., 24, 16761679, doi:10.1021/es00081a008, 1990.

Stephens, M., Turner, N., and Sandberg, J.: Particle Identification by Laser-Induced Incandescence in a Solid-State Laser Cavity, Appl. Opt, 42, 3726-3736, 2003.

Subramanian, R., Kok, G. L., Baumgardner, D., Clarke, A., Shinozuka, Y., Campos, T. L., Heizer, C. G., Stephens, B. B., de Foy, B., Voss, P. B., and Zaveri, R. A.: Black carbon over Mexico: the effect of atmospheric transport on mixing state, mass absorption cross-section, and BC / CO ratios, Atmos. Chem. Phys., 10, 219-237, doi:10.5194/acp-10-219-2010, 2010.

Taylor, J. W., Allan, J. D., Allen, G., Coe, H., Williams, P. I., Flynn, M. J., Le Breton, M., Muller, J. B. A., Percival, C. J., Oram, D., Forster, G., Lee, J. D., Rickard, A. R., Parrington, M., and Palmer, P. I.: Size-dependent wet removal of black carbon in Canadian biomass burning plumes, Atmos. Chem. Phys., 14, 13755-13771, doi:10.5194/acp-14-13755-2014, 2014.
Taylor, J. W., Allan, J. D., Liu, D., Flynn, M., Hayes, P. L., Jimenez, J. L., Lefer, B. L., Grossberg, N., Flynn, J., Gilman, J., de Gouw, J. A., and Coe, H.: Comparison of measured black carbon mass absorption coefficient to modelled values during CalNex 2010, J. Geophys. Res.-Atmos., in preparation, 2015.

Washenfelder, R. A., Young, C. J., Brown, S. S., Angevine, W. M., Atlas, E. L., Blake, D. R., Bon, D. M., Cubison, M. J., de Gouw, J. A., Dusanter, S., Flynn, J., Gilman, J. B., Graus, M., Griffith, S., Grossberg, N., Hayes, P. L., Jimenez, J. L., Kuster, W. C., Lefer, B. L., Pollack, I. B., Ryerson, T. B., Stark, H., Stevens, P. S., and Trainer, M. K.: The glyoxal budget and its contribution to organic aerosol for Los Angeles, California, during CalNex 2010, J. Geophys. Res., 116, D00V02, doi:10.1029/2011jd016314, 2011.

Weast, R. C.: CRC Handbook of Chemistry and Physics, 58th ed., CRC Press, Cleveland, Ohio, USA ET-58, 1977.

Yang, W.: Improved recursive algorithm for light scattering by a multilayered sphere, Appl. Opt., 42, 1710-1720, 2003.

Zhang, R., Khalizov, A. F., Pagels, J., Zhang, D., Xue, H., and McMurry, P. H.: Variability in morphology, hygroscopicity, and optical properties of soot aerosols during atmospheric processing., Proc. Natl. Acad. Sci. USA, 105, 10291-10296, doi:10.1073/pnas.0804860105, 2008. 